\title{
The development of attention and distractibility in preschool children from higher and lower socioeconomic status backgrounds
}

\author{
Hoyer, R.S. ${ }^{1}$, Pakulak, E. ${ }^{2}$, Bidet-Caulet, A. ${ }^{1}$, Karns, C.M ${ }^{3}$. \\ 1 Brain Dynamics and Cognition Team, Lyon Neuroscience Research Center; CRNL, INSERM U1028, CNRS \\ UMR5292, University of Lyon 1, Université de Lyon; Lyon, France. \\ ${ }^{2}$ Department of Child and Youth Studies, Stockholm University; Stockholm, Sweden. \\ ${ }^{3}$ Center on Brain Injuries Research and Training; Psychology Department, University of Oregon; Eugene, Oregon.
}

Attention is a multifaceted construct supported by multiple brain networks that undergo significant development in childhood. Child's abilities to select relevant information and to suppress distracting information are critical skills for school success. However, the developmental trajectory of these attentional abilities, and how external factors such as socioeconomic status (SES) influence them, has not been adequately characterized. We used the Competitive Attention Task (CAT) to simultaneously measure voluntary attention, distraction, phasic arousal, impulsivity and motor control in 4- and 5-year-old children from higher and lower SES backgrounds $(\mathrm{N}=72)$. Irrespective of age and SES, distracting sounds induce distraction and facilitation effects, as well as increased impulsivity, which is developmentally consistent with previous studies in older children and adults (Hoyer et. al., 2021). However, 4-year-old children from lower SES backgrounds presented significantly higher variability in response times, made more impulsive responses, and missed more targets than the higher SES group. These results indicate that multiple facets of attention contribute to distractibility in young children, and may inform evidence-based programs to compensate for attention differences in childhood. 


\section{Introduction}

In hearing children, the ability to listen to relevant auditory information and suppress distracting information is a foundational skill for learning and educational achievement (Stevens \& Bavelier, 2012). For example, in a typical classroom, a child needs to listen to a teacher's instructions or focus on a task when there are distractors in the environment, such as other children talking. The common term "paying attention" implies that attention is a unitary phenomenon but it is in fact a multifaceted construct supported by multiple brain networks. These networks undergo significant and differential development in childhood (Posner et al., 2014; Wetzel \& Schröger, 2014). The present study focuses on the development of behavioral correlates of attentional systems underlying distractibility during the preschool years. In addition, this study explores how environmental factors such as socioeconomic status (SES) influence the developmental trajectories of attention systems.

\section{$\underline{\text { Attention in Adults }}$}

Attention is Multifaceted. One classic brain-based model of attention includes three components: alerting, orienting, and executive networks (Posner et al., 2014; Posner \& Petersen, 1990; Posner, 1980, 2012). The alerting network is indexed by speeded response times following a general warning signal or by changes in arousal over the course of a prolonged task. It relies on brainstem and right-hemisphere systems to regulate the extent to which resources should be mobilized to react to salient events in the environment in a non-selective manner. The orienting network, which recruits frontal and parietal brain regions, supports the ability to direct attention toward a specific stimulus feature or spatial location (Corbetta \& Shulman, 2002). Orienting can consist of either voluntary responses toward relevant stimuli or involuntary responses toward irrelevant stimuli (Corbetta \& Shulman, 2002; Posner et al., 2014; Posner \& Petersen, 1990; Posner, 1980, 2012). Finally, the executive network is implicated in target detection; this system mobilizes limited-capacity brain resources to bring stimuli to awareness (Batterink et al. 2011) and monitor conflict (Botvinick et al., 2004; Checa et al., 2014; Mansouri et al., 2017). It is thought to rely on midline anterior cingulate cortex and lateral frontal cortex (Petersen \& Posner, 2012). In the context of a cognitively demanding task these systems ideally allow a person to focus attention on the task without being constantly distracted. 
Although dissociable, these major systems work together to meet endogenous task demands and to respond exogenously to the environment. For example, voluntary attention selects relevant features (Corbetta \& Shulman, 2002), locations (Posner, 1980), or modalities (Karns et al. 2009) and inhibits irrelevant ones (Broadbent, 1958; Deutsch \& Deutsch, 1963; Posner, 1980; Treisman \& Riley, 1969). In contrast, involuntary attention can be oriented toward unexpected salient stimuli, leading to distraction when the stimulus is irrelevant in the task context (Bidet-Caulet et al., 2015; Escera, Alho, et al., 2000; Näätänen, 1992). Moreover, voluntary attention orienting can be modulated by arousal (Keil et al., 2003).

Distractibility. The term 'distractibility' has been used to describe the state determining the propensity of isolated, unexpected, and task-irrelevant stimuli to disturb the voluntary attention mechanisms necessary for ongoing task performance (Bidet-Caulet et al., 2015; EIShafei et al., 2019; EIShafei, Fornoni, et al., 2018; Hoyer et al., 2021; Masson \& BidetCaulet, 2019). Meanwhile, voluntary mechanisms can modulate involuntary processes of attentional capture (EIShafei, Fornoni, et al., 2018; EIShafei et al., 2019). 'Distractibility' is thus a result of the balance between voluntary and involuntary attention orienting, and is influenced by the overall level of arousal (i.e. alertness). Whether involuntary capture of attention is beneficial or not depends on the context. In contrast to the focused state required for a challenging task, during a less demanding task, attention is available to respond to irrelevant and relevant stimuli. During everyday life, many basic tasks place few demands on executive attention (e.g., walking in the street toward a specific destination, listening to music, or pouring a cup of coffee). In such situations, where extensive cognitive resources are not required, it could be more advantageous to direct remaining available resources to respond to salient environmental stimuli such as potential dangers or opportunities for reward or discovering/learning.

'Distraction', distinct from distractibility, is a term used to describe the cognitive and behavioral impacts of a distractor on ongoing performance. When unexpected irrelevant salient stimuli induce distraction during a task, the reactive allocation of attention and resources toward the irrelevant event is followed by a reallocation of resources toward the task: altogether, these processes result in a behavioral cost (Bidet-Caulet et al., 2015; Escera, Alho, et al., 2000; Näätänen, 1992). But distractors may also trigger a burst of phasic (i.e., transient) arousal with behavioral benefits for some tasks (Bidet-Caulet et al., 2015; Masson \& Bidet-Caulet, 2019; Max et al., 2015; Näätänen, 1992; Wetzel et al., 2012, SanMiguel et al., 2010). This burst of arousal seems to be mediated by the norepinephrine 
system and to result in a transient and non-specific state of readiness to respond to any upcoming stimulus (Aston-Jones \& Cohen, 2005; Corbetta et al., 2008).

Distracting sounds thus generate a combination of facilitation and distraction effects, the final impact of which on performance depends on task demands (Kahneman, 1973; SanMiguel et al., 2010; Yerkes \& Dodson, 1908), sound properties (Parmentier \& Andrés, 2010; SanMiguel et al., 2010; Wetzel et al., 2012), and the sound-target delay (Bidet-Caulet et al., 2015; Masson \& Bidet-Caulet, 2019). The increase in reactivity induced by distracting sounds can also lead to an increased false alarm rate (Aston-Jones \& Cohen, 2005; Duncan et al., 2016). This phenomenon is related to impulsivity, which is the tendency to act without forethought (Barratt \& Patton, 1983; Stanford et al., 2009): an increased false alarm rate is indeed typically observed in impulsive people and might ensue from enhanced phasic arousal effect (Eysenck \& Eysenck, 1985; Houston \& Stanford, 2001; Zhang et al., 2015) coupled - or not - with reduced motor control (Booth et al., 2003; Kanaka et al., 2008; van den Wildenberg \& Crone, 2005; Wright et al., 2003).

Sustained attention. Because attentional systems depend on limited attentional resources, the ability to maintain attention on selected stimuli over time is another relevant construct. Sustained attention is defined as the ability to maintain active attentional engagement over time on a given task (Betts et al., 2006; Graziano et al., 2011; Oken et al., 2006; Parasuraman et al., 1989; Riccio et al., 1994). In adults, sustained attention varies over multiple time scales from rapid (across milliseconds) to slow (e.g., over a day) variations (Helfrich et al., 2018; Landau \& Fries, 2012), and these temporal modulations have been related to oscillations in different frequencies of ongoing neuronal activity (Clayton et al., 2015; Palva et al., 2013; Petton et al., 2018). Several models have been proposed to explain attentional fluctuations over time (reviewed in: Esterman \& Rothlein, 2019). One, the cognitive control theory, postulates that mind wandering is a default state to inhibit for individuals; this would lead attentional resources to be first allocated to this inhibition process, at the expense of ongoing behavioral performance, and could explain shorter-term variation in sustained attention efficiency. Another theory associates tonic arousal and attentional modulations (Lenartowicz et al., 2013; Unsworth \& Robison, 2017), speculating that attention control would fluctuate over time depending on the overall arousal level: attention performances could indeed be hindered when arousal iseither too high or too low. 


\section{Attention in Children}

Multifaceted attention in children. There is a common understanding that preschool children are highly distractible. Compared to adults, children's attentional capacities are more sensitive to irrelevant auditory interference from the local environment (Hoyer et al., 2021; Wetzel et al., 2006, 2016; Wetzel \& Schröger, 2014). It is known that the frontal lobe systems display a prolonged developmental time course (Gogtay, et al., 2004; Toga et al., 2006), so it is unsurprising that the immature executive system results in poorer conflict monitoring and control during childhood (Best \& Miller, 2010; Blakemore \& Choudhury, 2006). But given that attention relies on multiple systems in adults, the mechanisms underlying this immature attentional balance during early childhood still remain undefined. For example, poor performance during childhood could ensue from an immature voluntary orienting subsystem (Mezzacappa, 2004; Reis Lellis et al., 2013) leading to difficulties in sustaining attention (Betts et al., 2006; Kanaka et al., 2008; Lin et al., 1999; Thillay et al., 2015) or in inhibiting distractors (Booth et al., 2003; Howard et al., 2014), or from an immature involuntary orienting subsystem responding more strongly to irrelevant events (Wetzel et al., 2006, 2016, 2018; Wetzel \& Schröger, 2007). Another possibility is that protracted maturation of the alerting system leads to general over or under-arousal (Hernes et al., 2002; Lansink \& Richards, 1997; Wetzel et al., 2015). To resolve these questions, the different components contributing to distractibility need to be simultaneously assessed in children.

Voluntary and involuntary attention toward relevant objects appear to follow different maturational profiles during development (Farrant \& Uddin, 2015; Posner et al., 2014), but the precise developmental trajectory remains unclear. Different paradigms with endogenous cues that are either informative or uninformative have been used to measure the behavioral effect of voluntary orienting in anticipation of a target. Results are conflicting: some studies suggest that the capacity to voluntarily orient attention is mature before the age of four (Colombo, 2001; Johnson et al., 1991; Ross-Sheehy et al., 2015) while others show that the benefit in reaction time (RT) to targets following informative cues increases from four to six years of age (Hrabok et al., 2007; Mezzacappa, 2004; Posner et al., 2014; Rothbart et al., 2011). On the other hand, studies investigating involuntary orienting suggest that the RT benefit following exogenous informative cues is still maturing between six and nine years of age (Wainwright \& Bryson, 2002) and reaches a developmental plateau between 10 and 13 years of age (Lundwall et al., 2018). 
In line with Posner and colleagues' conceptual framework, the majority of developmental studies of attention have investigated the development of voluntary and involuntary orienting toward a relevant event (i.e., exogenous cues), while fewer studies have examined the development of involuntary orienting toward irrelevant events (i.e., exogenous distractors). Some studies of selective spatial attention, which refers to the ability to facilitate the processing of a relevant location of information while simultaneously inhibiting an irrelevant one, have suggested that involuntary orienting toward irrelevant stimuli may rely on different functional brain mechanisms in children and adults (Coch et al., 2005; Karns et al., 2015). Using a passive dichotic listening task with identical probes presented in attended and unattended streams, these studies have investigated the brain response to isolated and irrelevant events, while cognitive resources are recruited to inhibit a constant stream of irrelevant information. Theoretically, this paradigm invokes both voluntary and involuntary attention and can help to understand the brain correlates of distractibility. However, passive dichotic listening tasks do not provide behavioral measurements of the different attentional facets contributing to distractibility.

Distraction in children. The behavioral effects of involuntary orienting toward irrelevant events is typically investigated using audio-visual oddball paradigms, involving the discrimination of targets preceded by task-irrelevant standard or novel sounds, in school-aged children (Wetzel \& Schröger, 2014) and adults (Escera, Alho, et al., 2000; Wetzel et al., 2012). Distraction induced by irrelevant salient stimuli is measured by lower hit rates and longer RT to targets preceded by novel sounds. These measures improve from school age to adulthood (Olesen et al., 2007; Wetzel et al., 2006; Wetzel \& Schröger, 2007), suggesting a reduction in distractibility with age. To our knowledge, only one study has investigated the distraction effect on behavioral performance in preschool-aged children using an audio-visual oddball task, and results suggest that the deleterious effect of distraction progressively decreases during the preschool period, with a critical developmental step between ages four and five (Wetzel et al., 2018).

To date no study has investigated the developmental changes during the preschool years in the behavioral facilitation effect induced by distracting sounds. Phasic arousal has been mostly studied using physiological measurements as electrodermal activity, heart rate, or pupil dilation, during passive tasks in infants. An increase in electrodermal response to auditory stimulation has been observed in infants from the first day to the first year of life, suggesting a progressive increase in phasic arousal during this developmental period (Hernes et al., 2002). Moreover, the heart rate of children from 6 to 12-months of 
age has been found to rise in a distraction context (Lansink \& Richards, 1997), and increased pupil dilation to rare, unexpected and complex sounds has been observed in infants from 13 to 16 months of age compared to adults (Wetzel et al., 2015; Max et al., 2015).

Sustained attention in children. In preschool-aged children, sustained attention is commonly investigated using passive looking paradigms (Brandes-Aitken et al., 2019; Reynolds \& Romano, 2016; Richards \& Casey, 1991) and adaptations of the Continuous Performance Test (CPT; Conners, 2001; Mahone et al., 2001). Taken together, results from these studies suggest that sustained attention abilities emerge within the first years of life and continues to develop through adolescence (Brandes-Aitken et al., 2019; Hoyer et al., 2021; Kanaka et al., 2008; Reynolds \& Romano, 2016; Thillay et al., 2015). Differences in sustained attention efficiency between three and five years of age may result from an improvement in mobilizing attentional resources through alerting (Reynolds \& Romano, 2016; Richards \& Casey, 1991) and maintaining the focus on relevant information (Graziano et al., 2011; Ruff \& Capozzoli, 2003). Behaviorally, these developmental changes in attention are demonstrated with a progressive reduction of false alarm and missed response rates, as well as in RT variability, during detection tasks (Mahone et al., 2001). Few studies have investigated the impact of isolated distracting events on sustained attention ability; the small number of available studies suggests that efficient sustained attention abilities in children shield against deleterious effect of distraction (Oakes \& Tellinghuisen, 1994; Slobodin et al., 2015).

\section{The Competitive Attention Test}

The Competitive Attention Test (CAT) is a paradigm designed to assess the behavioral and brain correlates of distractibility (Bidet-Caulet et al., 2015). The advantage of this paradigm is that it combines the Posner task and oddball paradigm principles to provide simultaneous and dissociated measures of voluntary attention, distraction, phasic arousal, impulsivity and motor control in children and adults (Hoyer et al., 2021). To assess voluntary attention orienting, the CAT includes informative and uninformative visual cues toward the spatial location of a forthcoming auditory target. To measure distraction, the CAT includes trials with a task-irrelevant distracting sound preceding the target at several different delays. This change in distractor timing onset allows dissociation of the behavioral 
effects of facilitating phasic arousal (the difference between median RT in no-distractor and early-distractor conditions) and detrimental distraction (the difference between median $\mathrm{RT}$ in late- and early- distractor conditions). Based on previous results (Bidet-Caulet et al., 2015; Masson \& Bidet-Caulet, 2019), these differences can be interpreted respectively as good approximations of the facilitation and detrimental distraction effects triggered by so called distracting sounds (see Fig. A1 Appendix A). Results from studies in adults typically show that the voluntary orienting effect is manifested by a RT reduction in informative compared to uninformative trials, the distraction effect is manifested by increased RT in late compared to early-distractor condition, and finally the phasic arousal effect is indexed by a RT reduction in early distractor condition compared to no distractor condition.

In order to study the development of these facets of attention with more precision, the CAT was recently adapted for young children and used in a study of a large cohort of participants aged 6 to 25 years (Hoyer et al., 2021). In this study, the behavioral measurement parameters of the CAT were refined compared to those previously used in adults: RT variability and different types of erroneous responses can indeed be used as markers of attentional facets contributing to distractibility (see Table 2, Method section for a detailed presentation). Erroneous response types are particularly relevant markers to study the interaction between motor and attention systems, as this interaction is believed to underlie impulsivity and motor control.

In broader models of behavioral control, motor and attention systems are tightly linked: motor inhibition is driven by attentional selection, which is conditioned by past actions and their related memory traces (Diamond, 2013; Kahneman, 1973). Difficulties in motor inhibition can result in random motor responses, while impulsivity, which is the tendency to act without forethought, results in responses to task-irrelevant events such as distracting sounds or responses in anticipation of the targets. At the level of the brain, sensory and motor areas are typically the first to mature (Casey et al., 2005) with structural changes in the sensorimotor cortex which reach an adult-like functioning between late infancy and the pre-school period. However, motor control is dependent on many interconnections between cortical and sub-cortical regions of the brain (e.g., the prefrontal and lateral temporal cortices) which do not appear to reach a complete level of maturity until young adulthood (Gogtay et al., 2004). To that extent, motor control and impulsivity are likely to influence the motor response, which can in turn lead children to react randomly.

Results from our previous developmental study (Hoyer et al., 2021) showed that voluntary orienting is functional at 6 years of age, while the ability to sustain attention gradually develops from 8 to 12 years of age; interestingly, distraction is manifested as 
omissions (i.e., missed targets) of relevant stimuli in 6-7-year-olds and as impulsivity in 1112-year-olds. However, the RT distraction measure was not modulated by age, while the $\mathrm{RT}$ facilitation effect linked to phasic arousal is enhanced in 6-9-year-olds. This attentional imbalance, resulting in increased distractibility in children, may then be more related to reduced sustained attention capacities, enhanced distraction and increased arousal effects in childhood (6-8-year-olds), but to increased impulsivity in older children and adolescents (10-17-year-olds). Importantly, some measurements (e.g., missed responses, RT variability) show higher variability in younger children than in adults. A part of this variability may lie in environmental factors such as socioeconomic status.

\section{Socioeconomic Status}

Socioeconomic status (SES) is a proxy variable for variability in the early environment, typically assessed by a combination of parental education, occupational status, and/or household income. Disparities as a function of SES have been documented in a wide range of neurocognitive outcomes, and one of the neurocognitive systems most consistently associated with SES is self-regulation, including specific aspects of attention (e.g., Pakulak et al., 2018; Ursache \& Noble, 2016). While research is ongoing regarding specific aspects of the environment associated with SES that contribute to these findings at multiple levels of analysis (McEwen \& McEwen, 2017), evidence suggests that one predominant mechanism is chronic exposure to stress. Chronic stress may be particularly related to differences in regulatory development via the prefrontal cortex (McEwen \& Gianaros, 2010; McEwen \& McEwen, 2017).

Altered functioning of executive attention systems has been linked to reduced voluntary attention abilities (Diamond, 2013; Posner, 1980, 2012), and has been consistently reported in children and adolescents from lower SES (LSES) backgrounds (Farah, 2017; Farah et al., 2006; Noble et al., 2013). Event-related brain potential studies have also found differences in selective attention as a function of SES in adolescents (D'Angiulli et al., 2008; Hampton Wray et al., 2017; Stevens et al., 2009) and in preschool-aged children (Giuliano et al., 2018; Hampton Wray et al., 2017; Stevens et al., 2009). These studies have found that children from LSES backgrounds show an increased neuronal response to stimuli they are instructed to ignore, relative to children from higher SES (HSES) backgrounds. Moreover, the relationship between SES and brainresponse to distracting sounds is mediated by the sympathetic nervous system activity: the larger the sympathetic 
activity the better distractor suppression, suggesting a biological cost to achieve better cognitive performance - in this case better distractor suppression - for children from LSES backgrounds (Giuliano et al., 2018).

The effects of socioeconomic inequality begin early and persist during development. For example, behavioral signs of impulsivity in the first year of life persist into first grade only in children from LSES backgrounds (Meade, 1981); in this population, impulsivity in adolescence has also been linked to increased risk taking in early adulthood (Auger et al., 2010). Importantly, this pattern of results may represent a functional adaptation to environmental demands (e.g., increased sensitivity to potential threats) that may have deleterious effects in other environments (e.g., a classroom). In addition, these systems are amenable to evidence-based interventions targeting family stress as well as self-regulation and attention in preschool-aged children (Neville et al., 2013). In order to inform the refinement of such approaches and the development of novel approaches, it is crucial to improve our understanding of specific aspects of attention that contribute to distractibility in preschool-aged children from different SES backgrounds.

\section{$\underline{\text { The Current Study }}$}

As the development of distractibility during the preschool years is still an open question, the primary goal of the present study is to use the CAT task to characterize the simultaneous maturation of multiple aspects of attention in children from 3 to 5 -years of age from LSES and HSES backgrounds. Specifically, we examine the development of voluntary orienting and sustained attention, distraction, phasic arousal, impulsivity, and motor control, as well as potential differences in this development as a function of SES. Building on previous results in 6-year-olds (Hoyer et al., 2021) we hypothesized that (i) voluntary orienting, sustained attention and motor control abilities would increase with age, while in contrast (ii) distraction, phasic arousal, and impulsivity would decrease. More specifically, we expected younger children to present stronger behavioral manifestations of distractibility: an increased rate of responses to distractors and late and missed responses to targets following a distractor. We expected better voluntary attention performances (e.g., reduced RT variability, reduced late response and false alarm rates and larger cue effect on RTs in trials with no distractor) in older preschoolers. Additionally, we expected children from LSES backgrounds to show differences in attentional development; more specifically, a delayed development of voluntary attention functions, 
increased arousal and distraction effects in response to irrelevant sounds and enhanced impulsivity. In summary, we expected that distraction would decrease during early childhood, accompanied by an improvement in motor control and by a maturation of voluntary orienting and sustained attention, with a less mature profile in LSES children. 


\section{Methods}

\subsection{Participants}

Preschool children aged three to five years participated at their usual childcare site. All children had normal or corrected-to-normal vision. Parents were informed and provided signed informed consent on-site and children provided informed verbal assent prior to participation. With their permission, parents at each site were entered to win a $\$ 50$ gift card in a lottery regardless of whether they opted for their child to participate in the study. Children chose a small educational toy as a prize for participating in the study. Sites were associated with a university campus or were Head Start preschool sites (a U.S. program serving families living at or below the poverty line). Recruitment and study procedures were approved by the University of Oregon's Research Compliance Services and by participating schools.

Table 1 summarizes characteristics of the final sample. Although we tested 3-year-old children, experimenter field notes and visual inspection of the data indicated that the youngest children were not reliably completing the task so they were excluded from further analysis $(\mathrm{N}=14)$. Data from an additional 21 children were excluded because of noncompliance with instructions. A total of 71 subjects ( $51 \%$ female, 4 to 5 years of age) were included in the analysis. The recruitment site was used as a proxy measure to categorize children as LSES and HSES, since Head Start families must meet eligibility criteria related to economic disadvantage in order to be eligible for the program.

Table 1 | Characteristics of the population sample. Detailed samples by age (years and months), gender and SES.

\begin{tabular}{c:c|c|c|c|c}
\multicolumn{2}{c}{ Age } & Sample & Gender \\
\hline Range in years & Mean age in months & Included & Female & Male & Lower \\
\hline 4 to 4.9 & $\begin{array}{c}53.1 \\
\text { Hin }=48.0 ; \max =58.0)\end{array}$ & $\mathrm{n}=26$ & $53.8 \%$ & $46.2 \%$ & $50 \%$ \\
\hline 5 to 5.9 & $\begin{array}{c}64.2 \\
\text { (min }=60.0 ; \max =71.0)\end{array}$ & $\mathrm{n}=45$ & $48.9 \%$ & $51.1 \%$ & $66.6 \%$ \\
\hline
\end{tabular}




\subsection{Stimuli and task}

A blue fixation cross was presented at the center of a laptop screen. Participants were instructed to keep their eyes fixated on the cross during the task intervals between trial events. In $50 \%$ of the trials, a visual cue (200-ms duration) was followed, after a 940-ms delay, by a 200-ms duration target sound (Fig. 1a). The visual cue was presented centrally on a screen with a grey background and could either be a dog facing left, right, or to the front. The target sound was a recording of a dog barking monaurally presented in headphones. For the other $50 \%$ of the trials, the trial structure was identical, but a binaural distracting sound (300-ms duration) was played during the 940 ms delay period (Fig. 1b). A total of 18 different distracting sounds were used (phone ring, clock-alarm, etc.) for each participant. The distracting sound could be played at three different times during the delay: $200 \mathrm{~ms}$ (Dis1), $400 \mathrm{~ms}$ (Dis2) and $600 \mathrm{~ms}$ (Dis3) after cue offset, distributed equiprobably. Each distracting sound was played 4 times during the whole experiment, but no more than twice during each single block to limit habituation. All sounds were played at a comfortable level with distracting sounds louder than target sounds: target sounds played at $75 \mathrm{dBA}$ and Distracting sounds at $85 \mathrm{dBA}$. To compare behavioral responses to acoustically matched sounds, the same distracting sounds were played for each distractor condition (Dis1, Dis2 or Dis3) in the informative condition.

The proportion of cue categories (informative, uninformative) and target categories (NoDis, Dis) were distributed equiprobably between trials with and without distracting sounds. The informative condition represented $75 \%$ of the trials: in that case the dog was facing left or right, indicating the ear of the target sound presentation (37.5\% left and $37.5 \%$ right). The uninformative condition represented $25 \%$ of the trials: the facing-front dog was followed by the target sound in the left $(12.5 \%)$ or right $(12.5 \%)$ ear. Participants were instructed to perform a detection task by pressing a key as fast as possible when they heard the target sound (dog bark). They were asked to focus their attention to the cued side (for example, this was conveyed as follows to children: "But when the dog is looking to the right, he's telling you that he'll soon bark in your right ear. When he's looking to the left, he's telling you that he'll soon bark in your left ear;" see Appendix B for complete instructions). Participants were informed that informative cues were $100 \%$ predictive and that a distracting sound would sometimes be played. Feedback was given when participants correctly detected the target within 3300 ms after the target onset; a picture of a dog holding a bone (800-ms duration) was presented $500 \mathrm{~ms}$ after the response followed by the fixation cross for a randomized period of $1700 \mathrm{~ms}$ to $1900 \mathrm{~ms}$. If the participant did 
not respond in time, the fixation cross was displayed on the screen for an additional randomized delay of $100 \mathrm{~ms}$ to $300 \mathrm{~ms}$.

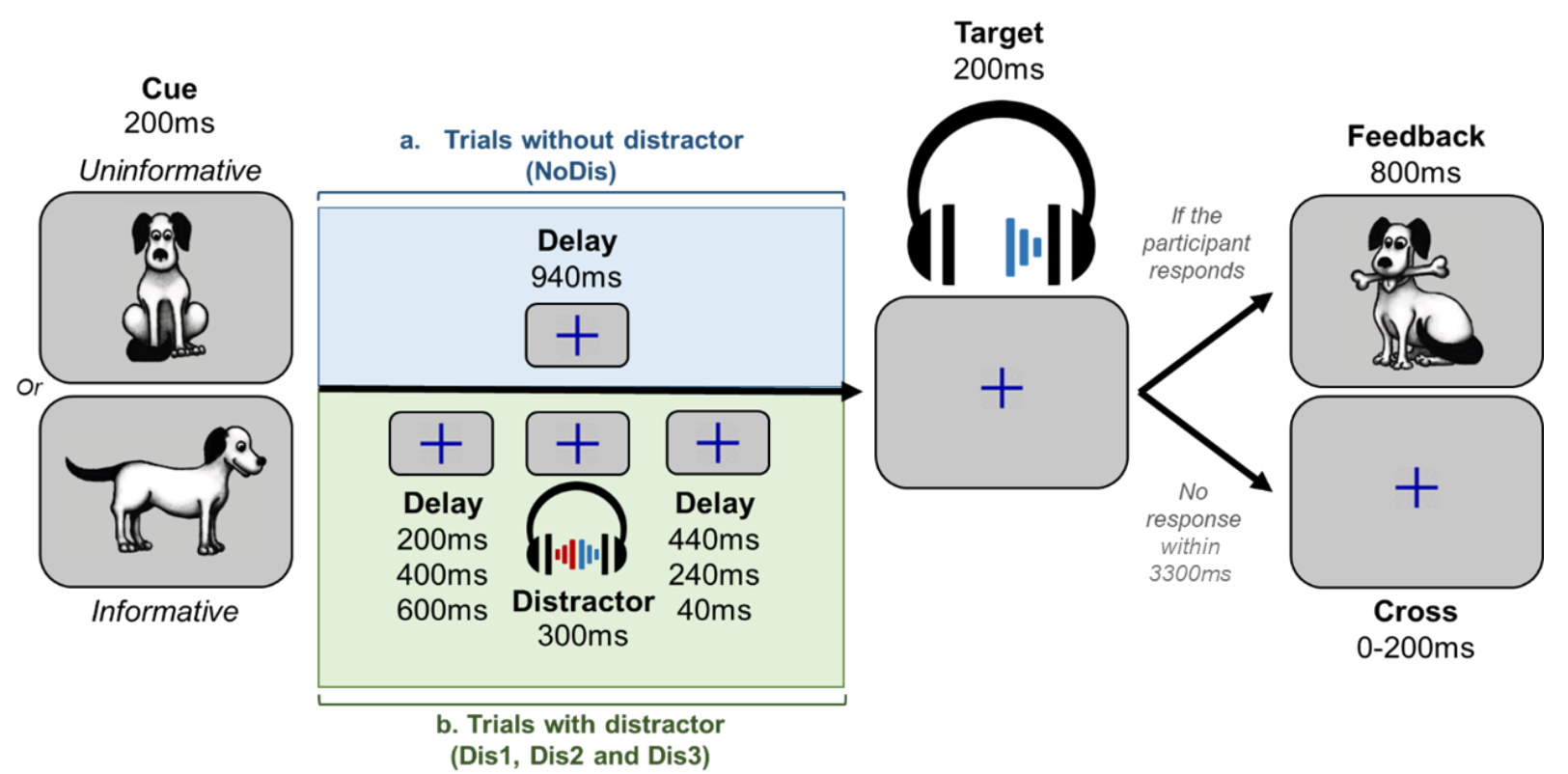

Fig. 1 | Protocol. a, In uninformative trials, a facing-front dog was used as visual cue (200 ms duration), indicating that the target sound would be played in either the left or right ear. In informative trials, a dog visual cue facing left or right (200 ms duration) indicated in which ear (left or right, respectively) the target sound will be played (200 ms duration) after a delay $(940 \mathrm{~ms})$. If the participant gave a correct answer within the $3300 \mathrm{~ms}$ post target offset, a feedback ( $800 \mathrm{~ms}$ duration) was displayed. $\mathbf{b}$, In trials with distractors the task was similar, but a binaural distracting sound ( 300 ms duration) - such as a phone ring - was played during the delay between cue and target. The distracting sound could equiprobably onset at three different times: $200 \mathrm{~ms}, 400 \mathrm{~ms}$, or $600 \mathrm{~ms}$ after the cue offset.

\subsection{Procedure}

Participants were tested in groups of two in a quiet room. Prior to the task, children were shown a treasure map containing four islands surrounded by the sea (see Fig. A2 Appendix B). They were informed that the game was to perform three blocks of the experiment to find a pirate's treasure. In each block they would 'help a dog find his bone' by pressing the button when they heard the dog bark and were told they should not press the button if they heard any other funny sounds. At the end of each block, children took a break to move a token from one to another island and, eventually, reach the treasure on the last island. During breaks, experimenters and children sang a nursery song while pretending to row to the next island. If children did not wish to complete all three blocks they still chose an educational toy to take home with them.

During the task, participants were seated in front of a laptop (approximately $50 \mathrm{~cm}$ from the screen) that presented pictures and sounds and recorded behavioral responses using 
Presentation software (Neurobehavioral Systems, Albany, CA, USA). Auditory stimuli were played in headphones. Participants performed three 4-minute blocks of 48 pseudorandomized trials each. The order of the three blocks was randomized across participants using a Latin square. The experimenter gave verbal instructions accompanied by visual illustrations of the task (see Fig. A3 Appendix B). Children were instructed to press a button on the keyboard with the hand that they mainly used when they draw or write their name. At the end of the first block, each participant verbally confirmed to the experimenter that they were able to distinctly hear the dog bark during the task. An experimental session lasted around 30 minutes.

\subsection{Measurement parameters}

We used a custom MATLAB program to extract and preprocess behavioral data. First, we visually inspected the reaction time $(R T)$ distribution relative to target onset for each age (see Fig. A4 Appendix C). The shortest RT for a correct response (RT lower limit) was calculated for each age range (see Fig. A4 and Appendix C). For each participant, the longest RT for a correct response (RT upper limit) was calculated from all RT > 0 ms using the Tukey method of leveraging the interquartile range. Correct response rate corresponds to the percentage of responses with a RT (relative to target onset) superior or equal to RT lower limit and inferior or equal to RT upper limit.

Eight behavioral measures were extracted for each child (Tab. 2. see also Fig. A5 Appendix D): 
Table 2 | Behavioral measurements, parameters for calculations and measured construct.

\begin{tabular}{|c|c|c|c|}
\hline Measure Abbreviation & Measure Name & Measure Description & Measured Construct \\
\hline RT & Reaction times & Positive response times & Overall processing speed \\
\hline RT SD & $\begin{array}{l}\text { Standard deviation of } \\
\text { reaction times }\end{array}$ & $\begin{array}{l}\text { Mean standard deviation of positive response times } \\
\text { in the NoDis condition for each block separately }\end{array}$ & $\begin{array}{l}\text { Variability in processing speed } \\
\text { Sustained attention }\end{array}$ \\
\hline LateRep & Late response & $\begin{array}{l}\text { Percentage of responses in the NoDis condition } \\
\text { during the period starting from the RT upper-limit to } 3300 \mathrm{~ms}\end{array}$ & $\begin{array}{l}\text { Slow processing error } \\
\text { Failure of short term sustained attention }\end{array}$ \\
\hline MissRep & Missed response & $\begin{array}{l}\text { Percentage of trials without any response made } \\
\text { during the entire trial duration up to } 3300 \mathrm{~ms} \text { post-target }\end{array}$ & $\begin{array}{c}\text { Error of omission } \\
\text { Lapse of sustained attention (NoDis) } \\
\text { Distraction (Dis) }\end{array}$ \\
\hline \multicolumn{4}{|c|}{ Behavioral measurements of attention effects on target expectancy } \\
\hline Measure Abbreviation & Measure Name & Measure Description & Measured Construct \\
\hline CueRep & Cue response & $\begin{array}{l}\text { Percentage of [incorrect or false-alarm] responses performed during } \\
\text { the } 150-450 \mathrm{~ms} \text { period post-cue onset }\end{array}$ & $\begin{array}{l}\text { Erroneous response to the cue } \\
\text { Impulsivity }\end{array}$ \\
\hline DisRep & Distractor response & $\begin{array}{l}\text { Percentage of responses performed during } \\
\text { the } 150-450 \mathrm{~ms} \text { period post-distractor onset }\end{array}$ & $\begin{array}{l}\text { Erroneous response to the distractor } \\
\text { Impulsivity }\end{array}$ \\
\hline AntRep & Anticipated response & $\begin{array}{l}\text { Percentage of responses performed: } \\
\text { In NoDis and Dis } 1 \text { : from } 300 \mathrm{~ms} \text { pre-target to the RT lower limit post-target } \\
\text { in Dis2: from } 150 \mathrm{~ms} \text { pre-target to the RT lower limit post-target } \\
\text { in Dis3: from } 100 \mathrm{~ms} \text { post-target to the RT lower limit post-target }\end{array}$ & $\begin{array}{l}\text { Erroneous response in anticipation of the target } \\
\qquad \text { Impulsivity }\end{array}$ \\
\hline RandRep & Random responses & $\begin{array}{l}\text { Percentage of responses performed in the remaining periods of the trials } \\
\text { within the } 150 \mathrm{~ms} \text { post-cue onset: } \\
\text { in NoDis: during the } 450 \text { to } 850 \mathrm{~ms} \text { period post-cue onset } \\
\text { in Dis } 1 \text { : during the } 450 \text { to } 550 \mathrm{~ms} \text { period post-cue onset } \\
\text { in Dis2: during the } 450 \text { to } 750 \mathrm{~ms} \text { period post-cue onset } \\
\text { in Dis3: during the } 450 \text { to } 950 \mathrm{~ms} \text { period post-cue onset }\end{array}$ & $\begin{array}{l}\text { Erroneous responses outside } \\
\text { of response parameters above }\end{array}$ \\
\hline
\end{tabular}

\subsection{Statistical analysis}

Behavioral data were analyzed using advanced multivariate statistical modelling.

\section{i. Sample characteristics}

Bayesian statistics were used to test the probabilistic certainty that the multivariate measures are related. Bayesian statistics were performed using JASP®) software (JASP Team (2018), JASP (Version 0.9) [Computer software]).

To confirm that our sample population was similarly distributed across age ranges in block order, gender, and SES, we performed Bayesian contingency table tests. We reported Bayes Factor $\left(\mathrm{BF}_{10}\right)$ as a relative measure of evidence. To interpret the strength of evidence in favor of the null model (uniform distribution), we considered a BF between 
0.33 and 1 as weak evidence, a BF between 0.1 and 0.33 as positive evidence, a BF between 0.01 and 0.1 as strong evidence and a BF lower than 0.01 as a decisive evidence. Similarly, to interpret the strength of evidence against the null model, we considered a BF between 1 and 3 as weak evidence, a BF between 3 and 10 as positive evidence, a BF between 10 and 100 as strong evidence and a BF higher than 100 as a decisive evidence (Lee \& Wagenmakers, 2013).

\section{ii. Behavioral data analysis}

Frequentist statistical approach. We expected large inter-individual variability in RT and response type rates as a function of condition. This behavioral response variability limits the comparison of data between conditions and means that data cannot simply be pooled for analysis. Generalized Linear Mixed Models (GLMM) are the best way to deal with such datasets, as they allow for correction of systematic variability (Bates et al., 2015). The heterogeneity of performance between subjects and experimental conditions was considered by defining them as effects with random intercepts and slopes, thus instructing the model to correct for any systematic differences in variability between the subjects (between-individual variability) and condition (between-condition variability). To confirm the need for mixed nested models, we used a likelihood ratio analysis to test the model fit before and after sequential addition of random effects. We used the Akaike Information Criterion and the Bayesian Information Criterion as estimators of the quality of the statistical models generated (Matuschek et al., 2017). To optimize our model, we checked the normality of the model residual.

To assess the impact of the manipulated task parameters (cue information and distractor type) and participant demographics characteristics (age and SES), on each type of behavioral measure (RT, RT SD, LateRep, MissRep, CueRep, DisRep, AntRep, RandRep), we analyzed the influence of four possible fixed effects (unless specified otherwise in the next section):

1) between-subject factor AGE: 2 levels (see Table 1);

2) between-subject factor SES: 2 levels (LSES and HSES);

3) within-subject factor CUE: 2 levels (CUE: informative vs. uninformative);

4) within-subject factor DISTRACTOR: 4 levels (NoDis, Dis1, Dis2 and Dis3), except for DisRep: 3 levels (Dis1, Dis2 and Dis3). 
A summary of the data and factors used in statistical modeling can be found in Table 2 . Note that for response types cumulating less than a mean of 10 observations across subjects (CueRep, DisRep and LateRep), we did not consider the within-subject factor DISTRACTOR in the analysis.

Because both fixed and random factors were taken into account in statistical modelling, we ran a type II analysis of variance. Wald chi-square tests were used for fixed effects in linear mixed-effects models (Fox \& Weisberg, 2018). We only considered the explanatory variables. The fixed effect represents the mean effect across all subjects after correction for variability. Frequentist models and statistics were performed in $\mathrm{R} \circledast 3.4 .1$ using the Ime4 (Bates et al., 2015) and car (Fox \& Weisberg, 2018) packages. We considered results of main analyses significant at $p<.05$.

When we found a significant main effect or interaction, Post-hoc Honest Significant Difference (HSD) tests were systematically performed using the emmeans package (emmeans version 1.3.2). P-values were considered as significant at $p<.05$ and were adjusted for the number of comparisons performed.

In the Results section, we report the SEM as the estimator of the distribution dispersion of the measures of interest, when not specified.

To ensure that analyses were performed on a sufficient number of trials per condition, participants with fewer than 12 trials with positive RT in each of the distractor conditions ( $N=6$ children from LSES background) were excluded from median RT analysis (leading to a total average of trials with positive RT of $49 \pm 1.8$ in NoDis, $16 \pm 0.7$ in Dis $1,15 \pm 0.6$ in Dis2 and $16 \pm 0.6$ in Dis3 conditions across the overall sample). Revised sample sizes for median RT analysis are: 4 year-olds: $n=23$ and 5 year-olds: $n=43$. The percentage of missing data over the total sample of included subjects in analyses is shown in Table 3.

Raw RT were log-transformed at the single trial scale for RT and RT SD analyses to be better fitted to a linear model with Gaussian family distribution; Response types were refitted to a linear model with binomial distribution without transformation (see Tab. 3 and Appendix E for additional details). 
bioRxiv preprint doi: https://doi.org/10.1101/2021.04.06.438161; this version posted April 8, 2021. The copyright holder for this preprint (which was not certified by peer review) is the author/funder, who has granted bioRxiv a license to display the preprint in perpetuity. It is made available under aCC-BY-NC-ND 4.0 International license.

Table 3 | Main statistical analyses according to behavioral response types. Experimental conditions, factors and models used as a function of the behavioral measurement. Detailed factor levels: Age $=4$ vs. 5 ; SES = LSES vs. HSES; CUE = informative vs. uninformative.

\begin{tabular}{|c|c|c|c|c|c|c|}
\hline \multirow{2}{*}{ Response type } & \multirow{2}{*}{$\begin{array}{l}\text { Condition(s) used for } \\
\text { response type calculation }\end{array}$} & \multicolumn{2}{|c|}{ Fixed factor(s) } & \multirow{2}{*}{ Random factor } & \multirow{2}{*}{$\begin{array}{l}\text { Distribution } \\
\text { fitting }\end{array}$} & \multirow{2}{*}{$\begin{array}{l}\text { Missing } \\
\text { data }\end{array}$} \\
\hline & & Between subjects & Within subjects & & & \\
\hline RT (log) & NoDis vs. Dis 1 vs. Dis2 vs. Dis3 & Age, SES & Cue, Distractor & Distractor, Subject & Gaussian & $8.5 \%$ \\
\hline RT SD (log) & NoDis & Age, SES & Block & Subject & Gaussian & $8.5 \%$ \\
\hline Late responses & NoDis & Age, SES & Cue & Subject & Binomial & $0.0 \%$ \\
\hline Missed responses & NoDis vs. Dis 1 vs. Dis2 vs. Dis3 & Age, SES & Cue, Distractor & Subject & Binomial & $0.0 \%$ \\
\hline Cue responses & NoDis \& Dis 1 \& Dis2 \& Dis3 & Age, SES & Cue & Subject & Binomial & $0.0 \%$ \\
\hline Distractor responses & Dis1 \& Dis2 \& Dis3 & Age, SES & Cue & Subject & Binomial & $0.0 \%$ \\
\hline Anticipated responses & NoDis vs. Dis 1 & Age, SES & Cue, Distractor & Distractor, Subject & Binomial & $0.0 \%$ \\
\hline Random responses & NoDis \& Dis 1 \& Dis2 \& Dis3 & Age, SES & Cue & Subject & Binomial & $0.0 \%$ \\
\hline
\end{tabular}




\section{Results}

\subsection{Sample characteristics}

Using Bayesian contingency table tests, we found positive evidence for a similar distribution in block order $(\mathrm{BF} 10=0.133)$ and gender $(\mathrm{BF} 10=0.323)$ across age ranges We observed weak evidence for a similar distribution in SES (BF10 $=0.746)$ across age.

\subsection{Behavioral Data}

For each type of behavioral measurement, we analyzed the influence of AGE, GENDER, SES, CUE, and DISTRACTOR factors (unless specified otherwise in the Table 3). In the following, when a factor was involved in a main effect and a higher order interaction, only the post-hoc analysis related to the interaction is specified.

\section{i. Reaction Times}

As expected, a main effect of AGE (X2 (1) = 6.45; $\mathrm{p}<.05)$ on median RT indicated that 4-year-old children $(985.0 \pm 73.0 \mathrm{~ms})$ were overall slower to respond than 5 -year-olds (768.6 $\pm 28.7 \mathrm{~ms})$. Irrespective of age, children were faster when the cue was informative $(833.6 \pm 32.7 \mathrm{~ms})$ rather than uninformative $(872.6 \pm 38.9 \mathrm{~ms}$; main effect of CUE: ( $X 2(1)$ $=4.32 ; \mathrm{p}<.05)$.

Consistent with our previous work in older children and adults, we observed a main effect of the DISTRACTOR ( $X 2(3)=180.4 ; p<.001$; see Fig. 2 ) on median RT. Post-hoc pairwise comparisons showed that distractors speeded the response to targets. RTs were slower in NoDis $(898.5 \pm 35.0 \mathrm{~ms})$ than in Dis1 (766.1 $\pm 39.0 \mathrm{~ms})$, Dis2 (801.5 $\pm 49.2 \mathrm{~ms})$ and Dis3 (848.2 $\pm 42.6 \mathrm{~ms}$ ) conditions. As shown in Figure 2, slower median RTs were observed in Dis3 compared to Dis1 and Dis2 conditions, whereas no difference was found between Dis1 and Dis2 conditions ( $p=.345)$. 
Fig. 2 | Median RT as a function of distractor condition. Mean of median reaction time as a function of the distractor condition [NoDis, Dis1, Dis2 and Dis 3$]\left(p<.05^{*}, p<.01^{* *}, p<.001^{* * *} ;\right.$ Error bars represent 1 SEM).

\section{ii. Standard deviation of reaction times}

Although we observed a main effect of AGE $(X 2(1)=5.5 ; p<.05)$ on response time variability (RT SD), this should be interpreted in light of a significant three-way AGE by BLOCK by SES interaction ( $X 2(2)=7.3 ; p<.05$; Fig. 3). Irrespective of the SES, post-hoc analysis revealed that children of 4 years of age $(634.8 \pm 61.7 \mathrm{~ms})$ had increased RT SD compared to their older peers $(462.2 \pm 35.5 \mathrm{~ms} ; \mathrm{p}<$. 01). The 4-year-old children from LSES sites, only, showed higher RT SD during the third block (565.7 $\pm 62.6 \mathrm{~ms}$ ) compared to the first one (840.1 $\pm 89.7 \mathrm{~ms})$. Moreover, on the third block only, 4-year-old children from LSES sites showed higher RT SD than their 4-year-old peers from HSES background (463.7 $\pm 44.2 \mathrm{~ms})$. 
RT SD (NoDis) by bloc according to age and SES

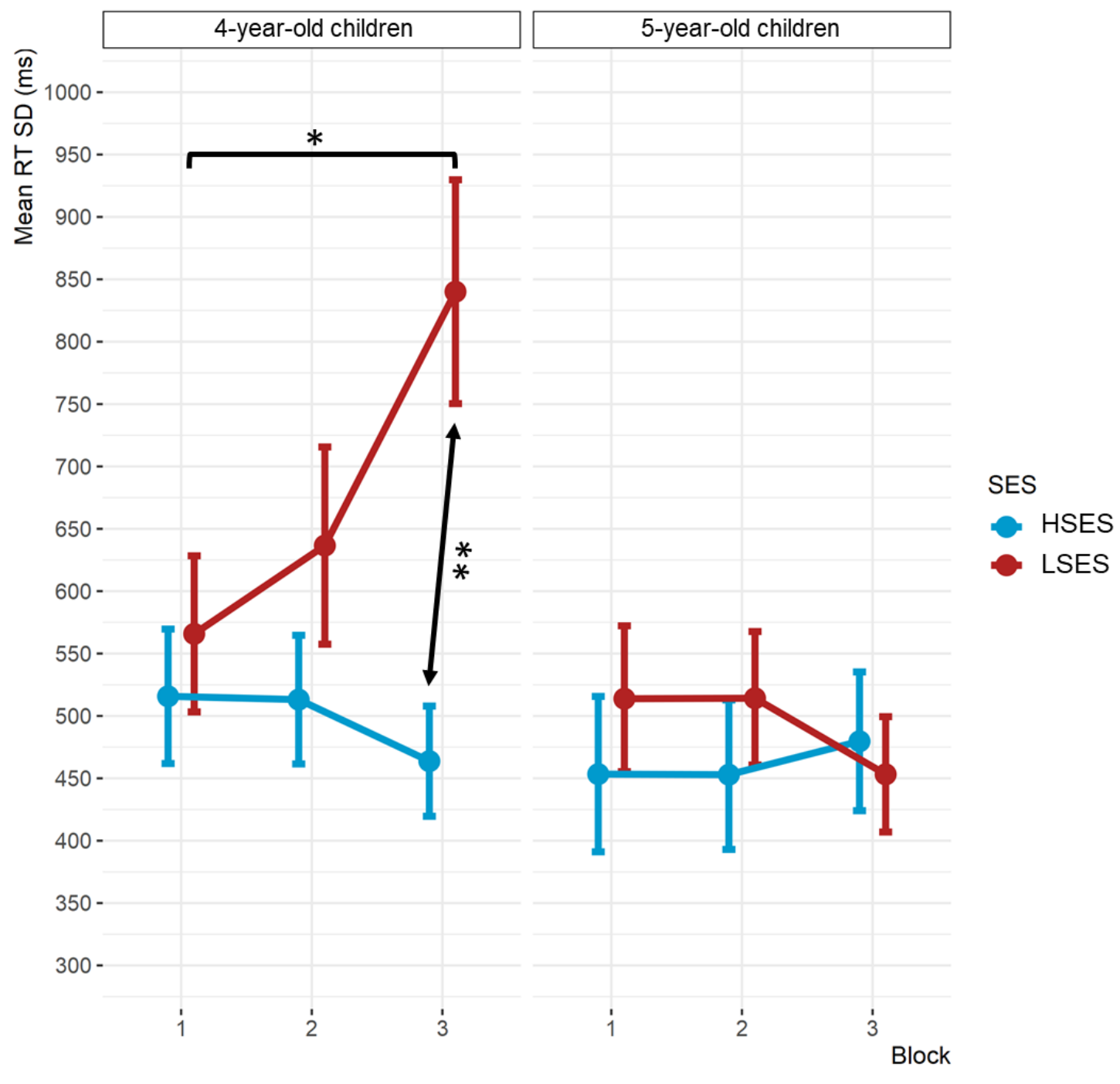

Fig. 3 | Mean RT SD in NoDis condition by block as a function of age. Mean of median reaction time as a function of the block ( $1^{\text {st }}, 2^{\text {nd }}$ and $\left.3^{\text {rd }}\right)$, by SES (HSES = higher SES, LSES = Lower SES) and age (4-year-olds on the left and 5-year-olds on the right). $\left(p<.05^{*}, p<.01^{* *}, p<.001^{* * *}\right.$; Error bars represent 1 SEM).

\section{iii. Global accuracy}

The proportion of the different types of behavioral responses according to age is depicted in Fig. 4. The average correct response rate was $50.7 \pm 2.2 \%$. No main effect of AGE or SES, nor interaction with AGE or SES, was found for LateRep (total average: 9.9 $\pm 0.6 \%$; Fig. A6b Appendix F), RandRep (total average: $6.0 \pm 0.7 \%$; Fig. A7b Appendix G), DisRep (total average: $5.9 \pm 0.9 \%$; Fig. A7c Appendix G), or AntRep (total average: 13.8 $\pm 1.1 \%$; Fig. A7d Appendix G). Significant effects of age and SES on the other response types are detailed in the following sections. 

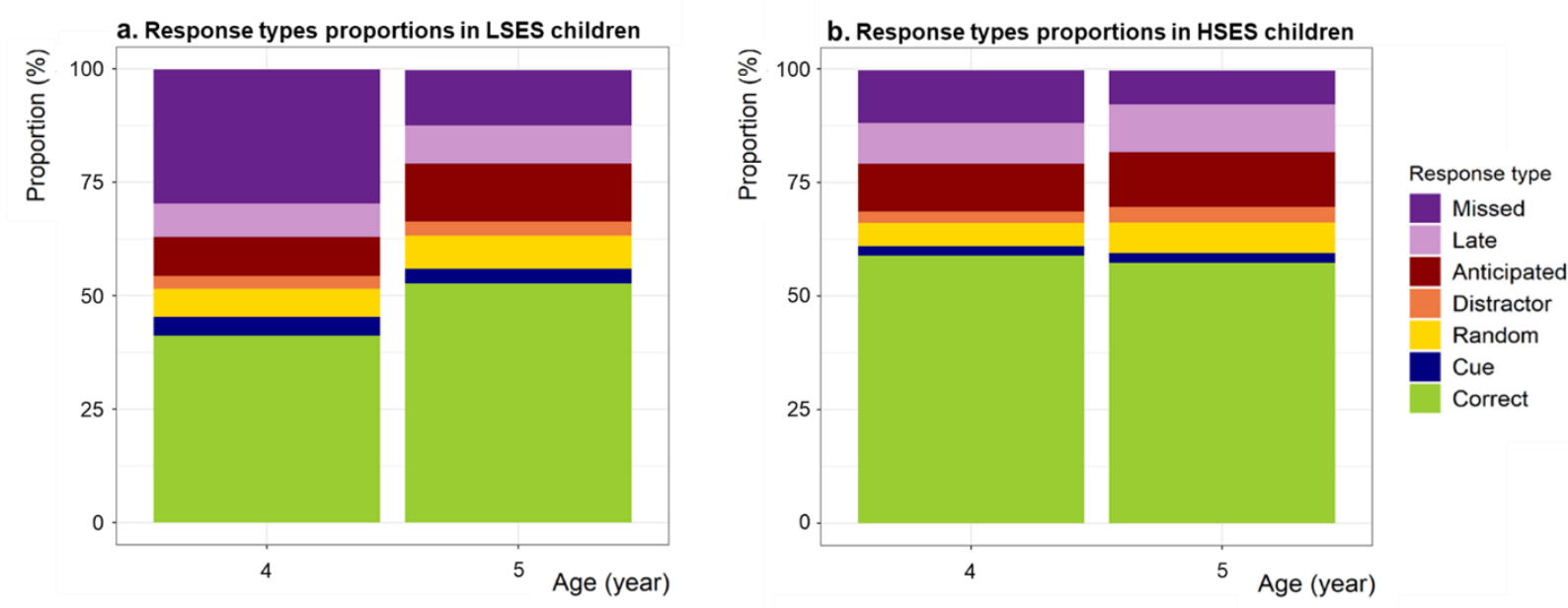

Fig. 4 | Response types proportions as a function of age and SES. Response type proportions for a) LSES and b) HSES groups. (HSES = higher SES, LSES $=$ Lower SES).

\section{iv. Erroneous responses to cue}

The rate of cue responses (CueRep, $2.9 \pm 0.4 \%$ on average) was modulated by SES $(X 2(1)=7.0 ; p<.01)$. A CUE by SES interaction was also significant $(X 2(1)=6.8 ; p<.01$, Fig. 5). Post-hoc analysis revealed that children from the LSES group (3.7 $\pm 0.5 \%)$ made more CueRep than children in the HSES group $(1.6 \pm 0.5 \%)$ irrespective of the validity content of the cue. Additionally, children from HSES backgrounds made more CueRep in the informative condition $(2.2 \pm 0.6 \%)$ compared to the uninformative one $(0.9 \pm 0.4 \%)$.

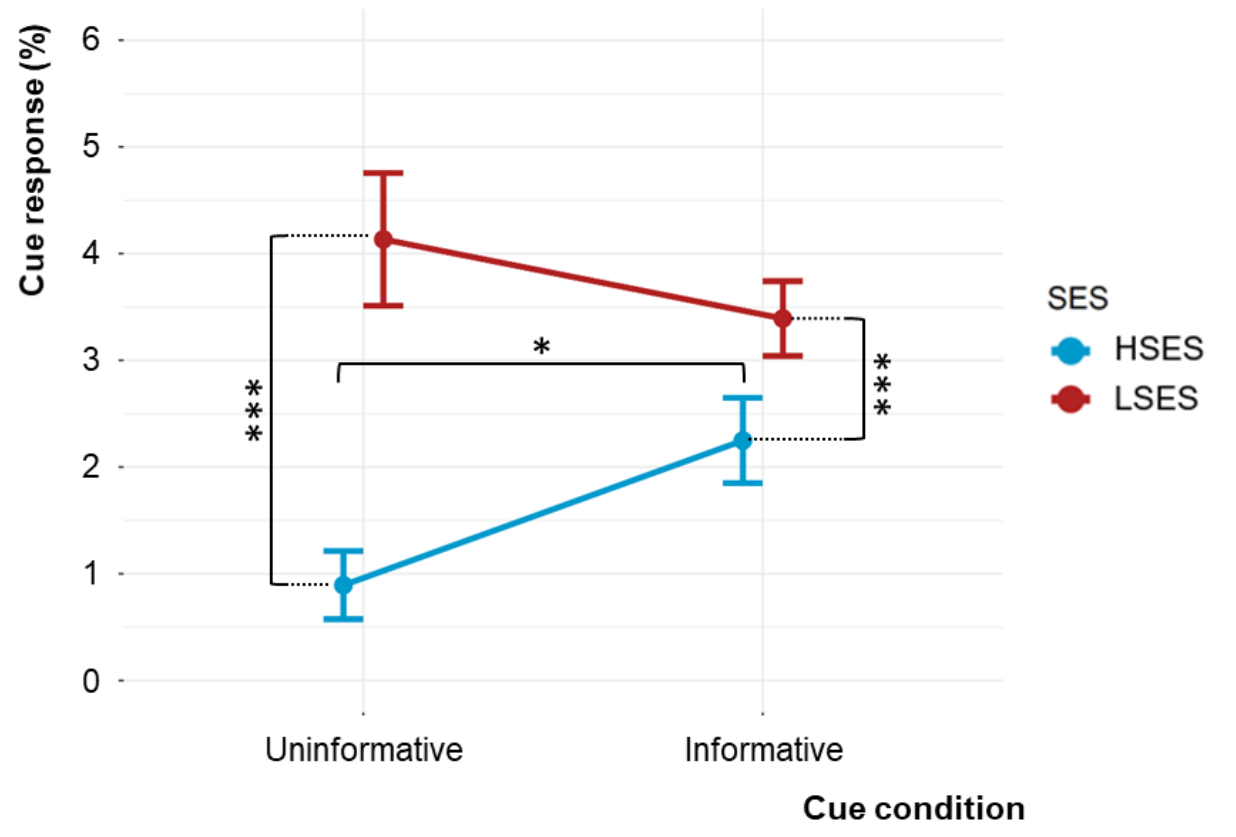


Fig. 5 | Cue response by cue condition as a function of SES. Mean percentage of cue response as a function of cue type (informative and uninformative) and (HSES $=$ higher SES, LSES $=$ Lower SES). $\left(p<.05^{*}, p<.01^{* *}, p<.001^{* * *}\right.$; Error bars represent 1 SEM).

\section{v. Erroneous responses in anticipation of target}

The rate of anticipated responses (AntRep, $13.8 \pm 1.1 \%$ on average) was modulated by DISTRACTOR $(X 2(1)=46.0 ; p<.001)$. Children had higher proportions of AntRep in Dis1 $(18.7 \pm 1.8 \%)$ than in NoDis condition $(8.9 \pm 0.9 \%)$ regardless of age and SES.

\section{vi. Missed responses}

The rate of missed responses (MissRep, $15.1 \pm 1.5 \%$ on average) was modulated by AGE $(X 2(1)=15.4 ; p<.001)$ : 4-year-olds $(21.4 \pm 3.2 \%)$ made more MissRep than 5-yearolds (1.3 $\pm 1.3 \%$ ) (Fig. A6a Appendix F).

We also observed significant main effects of SES $(X 2(1)=15.0 ; p<.001)$, as well as a significant DISTRACTOR by SES interaction $(X 2(3)=8.5 ; p<.05$; Fig. 6$)$. According to HSD post-hoc comparisons, and irrespective of the distractor condition, participants from LSES backgrounds $(9.6 \pm 1.6 \%)$ made more MissRep than participants from HSES backgrounds (18.6 $\pm 1.2 \%$ ). Additionally, only children from HSES made more MissRep in the Dis3 condition (12.4 $\pm 1.7 \%$ ) compared to the Dis1 condition $(7.7 \pm 1.5 \%)$.

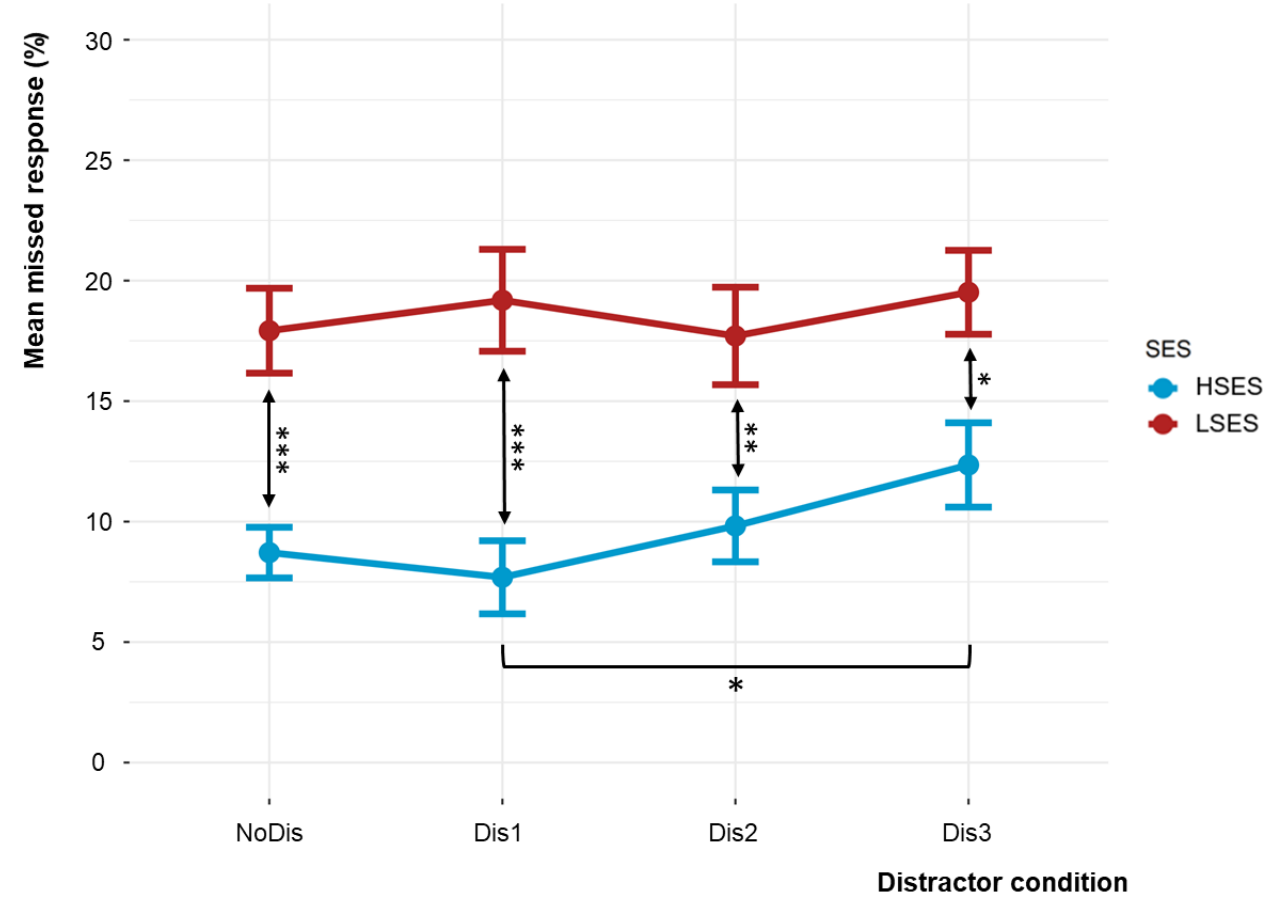

Fig. 6 | Missed response by distraction condition as a function of SES. Mean percentage of missed response as a function of cue (informative and uninformative) and SES (HSES = higher SES, LSES $=$ Lower SES). $\left(p<.05^{*}, p<.01^{\star *}, p<.001^{* \star *}\right.$; Error bars represent 1 SEM). 


\section{Discussion}

The present study aimed at characterizing different components of attention and distraction in young children and to determine the extent to which SES impacts the development of these components in early childhood. Consistent with our previous work in older children and adults, we found in both 4- and 5-year-old children (1) a facilitation of RT after informative cues or early distractors (2) a cost in RT after late distractors, (3) a higher proportion of anticipated responses in the presence rather than in the absence of a distractor, suggesting that this paradigm is a valid measure of these constructs in younger children (see Fig. A8 Appendix $\mathrm{H}$ ). In addition, 4- and 5-year-old children showed a high proportion of random responses, indicating a weak motor control, and a high variability in $\mathrm{RT}$, suggesting difficulties in sustaining attention. Finally, children from 5-year-olds are faster to detect target sounds and missed less of them than their 4-year-olds peers, whether or not relevant sounds are preceded by a distractor.

We also compared 4- and 5-year-old children from HSES and LSES backgrounds and found several differences as a function of SES. Four-year-old children from LSES backgrounds had higher variability in response times, although this difference disappeared at 5-year-old. SES differences were also found in the proportion of erroneous responses. Children from the LSES group made more erroneous responses to the cue and missed more targets than children from the HSES group, suggesting greater impulsivity and reduced sustained attention in the LSES group.

Below, we discuss the implications of these findings, and caveats to our conclusions.

\subsection{General development of attention with age}

Although there is an established literature on multifaceted components of attention in children, few studies have focused on the development of specific aspects of distractibility in the preschool age, a time when attention systems are rapidly developing (Posner et al., 2014; Rothbart et al., 2011; Rueda et al., 2004).

Voluntary orienting toward relevant stimuli. Both 4 and 5 year-old groups were found faster after an informative rather than an uninformative cue, irrespective of the SES. This finding suggests similar attention orienting abilities at 4 and 5 year old, regardless of the SES. Voluntary attention orienting has previously been found either stable (Federico et al., 2017; Mullane et al., 2016; Ross-Sheehy et al., 2015; Rueda et al., 2004) or increasing 
(Commodari, 2016; Mezzacappa, 2004; Reis Lellis et al., 2013) in efficiency from 5 to 10 years of age. The present results would then be an additional argument in favor of an early maturation of attentional orienting. Further studies are however needed to elucidate the discrepancy in results regarding voluntary orienting development in children.

Distraction and Facilitation due to Arousal in Children. The strength of the CAT lies in the differential timing of distractor sounds before the target, allowing the dissociation of the behavioral costs and benefits they induce. In line with previous studies using the CAT in adults (Bidet-Caulet et al., 2015; EIShafei, Bouet, et al., 2018; EIShafei et al., 2019; Masson \& Bidet-Caulet, 2019), we observed two distinct effects on RTs triggered by the distracting sounds. First, distracting sounds played long before the target (Dis1 and Dis2) speeded RT compared to a condition without distractor (NoDis): this benefit in RT has been attributed to an increase in phasic arousal (Masson \& Bidet-Caulet, 2019). Second, distracting sounds played just before the target (Dis3) slowed RT compared to conditions with a distractor played earlier (Dis1 and Dis2): this cost in RT is considered a good behavioral approximation of distraction (Bidet-Caulet et al., 2015; ElShafei et al., 2019; Hoyer et al., 2021; Masson \& Bidet-Caulet, 2019).

Both phasic arousal and distraction effects were observed between 4 and 5-year-olds. This suggests that the CAT permits the dissociation of arousal and distraction effects in preschool-aged children in a similar manner as in school-aged children and adults (Hoyer et al., 2021; Masson \& Bidet-Caulet, 2021). The developmental trajectories of these two effects were previously found to be different during the school age (Hoyer et al., 2021). The present study extends these findings by showing that both the arousal and distraction effects can be dissociated and are observable during the preschool period.

Previous results suggest that the physiological effect of phasic arousal is observable even before the first year of life; findings from the present study bolster this assumption by revealing that increased phasic arousal following a distractor facilitates the processing of the subsequent target in both 4 and 5-year-old children. Furthermore, phasic arousal depends on sound properties (Max et al., 2015; Wetzel et al., 2012) and the level of tonic arousal (Aston-Jones \& Cohen, 2005; Howells et al., 2012) which is in turn influenced by the task demands (M. Eysenck, 1982; Kahneman, 1973; Yerkes \& Dodson, 1908). It would be interesting to consider these factors in future research to refine the understanding of phasic arousal effects on behavior in 4- and 5- year-olds. Although the arousal effect on RT was not found different between 4 and 5-year-olds, it is nevertheless interesting to note that the arousal facilitation effect was found to be stable from 6 - to 8 years, and then to 
progressively decrease from 9 to 13 years before reaching adult-like efficiency at age 14 (Hoyer et al., 2021) (see Fig. A8 Appendix H).

So far, few studies have investigated the development of distraction in preschool-aged children using active behavioral tasks. Recent results from oddball paradigms, however, suggest that distraction effects are greater in 4- compared to 5-year-old children, and progressively decrease from childhood to adulthood (Wetzel et al., 2018). On the contrary, using the CAT, the RT distraction effect is found similar between 4 and 5-year-olds in the present study, and from 6 to adulthood in a previous one (Hoyer et al., 2021). This discrepancy may be explained by differences in protocols. Discrimination (Oddball task; Wetzel et al., 2018) is more demanding than detection (CAT): it could then be easier for 4-year-old children to deal with distracting information during detection tasks compared to discrimination tasks. Taken together, these results then suggest that the amount of available cognitive resources increases from 4 to 5 -year-old and help children to ignore distracting information.

The present results suggest that phasic arousal and distraction may not improve during the preschool age. However, the precise relationship between arousal and distraction still needs to be characterized, since CAT measures should not be considered as markers of independent cognitive functions, but as complementary measures of the impact of distractors on performance.

Motor Control and Impulsivity in Children. In the CAT paradigm, cue, distractor and random responses are conceptualized as complementary measures of impulsivity and motor control. We hypothesized that impulsivity and motor control would decrease during the preschool period. However, the present findings indicate that none of these measures were modulated by age, suggesting that impulsivity and motor control efficiency are not different from 4 to 5 years of age. Previous research mostly used subjective teacher and parent self-report measures and/or objective measures from child-friendly versions of CPT, Go-NoGo, and Stop Signal tasks, all of which solicit the ability to inhibit an ongoing motor response when a rare distractor occurs. Results from past studies are contradictory: some findings indicate that behavioral indices of impulsivity and motor control decrease and increase, respectively, between three and six years of age (Carver et al., 2001; Kanaka et al., 2008; Tao et al., 2014; Tillman et al., 2007; Wiebe et al., 2012), while others did not observe significant differences between three and five years of age (Mahone et al., 2001; McGoey et al., 2007).

It is important to note that these processes occur within a behavioral context where different aspects of the task affect others. For example, the mean rate of anticipated 
responses is quite variable during the preschool age and participants made more anticipated responses to the target in presence of a distractor, suggesting that processes triggered by distractors influence the behavioral expression of anticipated responses. These anticipatory responses following distracting sounds could be either driven by the phasic arousal increase triggered by distractors or by reduced voluntary inhibitory motor processes.

Sustained Attention in Children. The number of missed responses in attentional tasks is a sensitive measure of sustained attention over long time periods (Kanaka et al., 2008), while the proportion of late responses is considered to be an index of short-term sustained attention (Hoyer et al., 2021; Petton et al., 2018). In the present study, and irrespective of the distractor condition, 4-year-old children showed reduced sustained attention abilities when compared with their 5-year-old peers as indexed by an enhanced missed response rate. However, no effect of age was observed for the late response type, suggesting that children's ability to maintain attention over shorter time periods is stable from 4 to 5 years of age. A decrease in missed responses from 4 to 5 years of age is then more likely to be the result of lower tonic arousal levels in the younger age group. Furthermore, 3-year-old children were excluded from analysis due to their random behavioral performance in the CAT task: an inability to adequately perform the task at 3 years of age could also be explained by reduced sustained attention ability, as previously observed in the literature (Mahone et al., 2001). To that extent, sustained attention ability at 3 years of age would be too precarious to enable children to perform the CAT task, but with the rapid brain maturation occurring during the preschool years, and particularly at age four (Brown \& Jernigan, 2012), children at that age have sufficient sustained attention abilities to perform the task, and improvements in performance are found at age five.

\subsection{Development of distractibility as a function of SES}

Previous research has found relationships between SES and a wide range of neurocognitive measures across development, and one of the most consistent is between SES and self-regulation, including attention (Pakulak et al., 2018; Ursache \& Noble, 2016). Here we extend these findings by documenting relationships between SES and distraction, sustained attention, as well as motor control and impulsivity during a crucial period in the development of these skills and related brain systems. 
Distraction. Distraction can result in enhanced RT, late response or even miss responses in trials with distracting sounds. No effect of SES was found on RT distraction effect nor on late response rates. Importantly, the HSES group showed increased missed response rates in trials with a short distractor-target interval (Dis3) compared to condition without distractors, suggesting a strong impact of distracting sounds in 4 and 5 -year-olds with HSES, similar to the effects observed in 6- and 7-year-olds children in a previous study (Hoyer \& al., 2021). A different pattern was found in the LSES group: similar amounts of miss responses irrespective of the distractor condition. These results suggest that LSES children would be as much inattentive in environments with or without auditory distracting information because of reduced global sustained attention abilities, while HSES children would tend to miss more targets in distractor conditions. Therefore, the present study do not provide clear argument for increased distraction with LSES.

This result is quite in contradiction with previous research attempting to characterize behavioral differences in attention during the preschool years and as a function of SES are relatively rare. Results from ERP studies of auditory selective attention have found that the neuronal response associated with the suppression of distracting information is particularly sensitive to differences associated with SES such that the response to distractors is typically larger in children from LSES backgrounds, suggesting reduced ability to suppress distraction (Stevens et al., 2009; Giuliano et al., 2018; Hampton Wray et al., 2017). This discrepancy may be explained, at least in part, by differences in the tasks used to assess attentional capacities. Studies suggesting a reduced ability to suppress distractors processing in LSES children have used a dichotic listening task during which two stories were simultaneously played to the child, with the child instructed to attend one story and ignore the other, and with identical probe sounds superimposed on both stories. Behaviorally, this paradigm probes the child's ability to inhibit the continuous stream of distraction from the unattended channel, but also unexpected and isolated probe sounds. One can then imagine than the more demanding the task, the more the child will need to recruit the executive system to deal with its requirements. Because children from LSES backgrounds have consistently been found to perform worse on executive function tasks, which may be related to a delay in the development of the prefrontal cortices (Lawson et al., 2013; Noble et al., 2012), children from LSES backgrounds might present difficulties in suppressing distractors only when performing demanding tasks (i.e. more demanding than the CAT used in the present study) which to some degree require increased recruitment of the executive system. 
Recent findings also suggest that for children from LSES backgrounds there may be a potential biological cost of achieving performance similar to their peers from HSES backgrounds. Children from LSES backgrounds who show brain responses to distractors similar to their peers from HSES backgrounds seem to accomplish this via activation of the sympathetic nervous system resulting in a heightened alert state that would contribute to distractor suppression (Giuliano et al., 2018). It is thus possible that children from LSES backgrounds do not show differences miss response rates in trials with or without distractors as a result of an overall heightened state of alertness, in contrast to an effect more specific to the presence of distractors in children from HSES backgrounds. Future research combining the CAT paradigm with measures of autonomic nervous system function in samples from a wide range of SES backgrounds will shed light on this possibility.

Sustained attention. Compared to their peers from HSES backgrounds, we found evidence that both 4- and 5-year-olds children from LSES had more difficulty in sustaining attention as they missed more targets irrespective of the distractor condition. Additionally, we documented increased variability in RT across experimental blocks in 4-year-old children in the LSES group, such that RT SD almost doubled between the first and third blocks in this group. Previous studies using a child-friendly ERP paradigm assessing sustained selective auditory attention have found differences in brain function for selective attention as a function of SES in this age group (Stevens et al., 2009; Hampton-Wray et al., 2017, Giuliano et al., 2018); consistent with the present results, evidence from one study suggests that SES differences evident at age four fade by age five (Hampton-Wray et al., 2017). Evidence also suggests that preschool-aged children from LSES backgrounds show differential functional maturation of prefrontal cortices (Lawson et al., 2013; Noble et al., 2012). Taken together, this suggests that preschool-aged children from LSES backgrounds show an attentional imbalance characterized by reduced voluntary sustained attention in particular at age four. Importantly, rather than being considered a deficit, this attentional imbalance could reflect an adaptive attentional maturation. LSES environments are typically more chaotic and unpredictable, and in such environments, it would be adaptive to regularly interrupt ongoing voluntary attention processes to maintain a more constant reactivity to possible changes in the environment.

Motor control and impulsivity. Motor control and impulsivity are sometimes used interchangeably, as dissociating their behavioral effects is challenging. In clinical settings, when assessing Attention Deficit Disorder, these two components are combined within the 
Impulsivity/Hyperactivity category of symptoms (Diagnostic and statistical manual of mental disorders, 2013). Impulsivity refers to the tendency to react to irrelevant stimuli or prior to targets occurrence, while motor control refers to the voluntary control of motor function even in absence of any stimuli. In the CAT, cue responses are conceptualized as a possible operationalization of impulsivity. Children from LSES backgrounds made significantly more cue responses than their peers from HSES backgrounds, who also showed more cue responses in informative than uninformative trials. These findings thus suggest that children from LSES backgrounds may be more impulsive. As discussed above, this tendency to react to irrelevant stimuli could reflect an adaptive response in certain contexts, such as the need to maintain alertness to potential threats in more chaotic and unpredictable environments. Children from HSES backgrounds, in contrast, are more likely to respond impulsively to relevant - but non-target - stimuli if they are highly predictive of the forthcoming target. However, this interpretation should be considered with caution because cue responses have not been identified as a behavioral marker of interest in assessing attentional balance and impulsivity in a school-age sample (Hoyer et al., 2021). This highlights the need for further research to precisely identify what types of attentional markers reflect the efficiency of a given cognitive function at each stage of development.

\subsection{Limitations of the present study}

Findings from this study provide evidence of maturational differences in attentional facets underling distractibility in preschool-aged children from LSES and HSES backgrounds. There are, however, several limitations to the current study. First, the protocol used does not provide measures of stress and motivation nor tonic arousal: these factors are believed to influence attentional performance and they should be taken into account in further studies. Second, this cross-sectional study allowed for age group comparisons but did not provide longitudinal data. Further studies are then needed to characterize individual variability in attention performance and to better identify predictors of attentional efficiency in children and examine developmental trajectories of efficiency in the same participants. Third, SES was defined by proxy using the school affiliation of the child, limiting the ability to characterize and control for variability within SES. 


\subsection{Conclusion and future directions}

To our knowledge, this is the first study to examine specific developmental trajectories of several facets of distractibility during the preschool age.

Results show that 4-year-old children have reduced voluntary sustained attention ability compared to their 5-year-old peers as indexed by a larger amount of missed responses. Sustaining attention over time was found to be more difficult for children coming from LSES backgrounds, particularly at age four, as indicated by increased variability in reaction times and miss response rates. Moreover, children from the LSES group made more erroneous responses to the cue than children from the HSES group, suggesting greater impulsivity. No evidence for enhanced distraction in LSES could be found.

Taken together, these findings suggest that the development of distractibility is adaptive: in a predictable and safe environment, young children from HSES backgrounds are able to sustain their attention to achieve goals, but their performance can be impeded by the occurrence of isolated irrelevant events in the environment. In contrast, children from LSES backgrounds show reduced sustained attention ability. To compensate for difficulties created by this inability to maintain attentional orienting on relevant events, children from LSES backgrounds might importantly enhance tonic arousal, whose effect would contribute to increased distractor suppression, helping children from LSES to shield against distraction (Giuliano et al., 2018). These results indicate that distractibility progressively develops during the preschool age, and consistent with evidence from other paradigms suggest that adversity related to SES can modulate attentional performance in younger children. Elucidating differences in distractibility during the preschool age as a function of SES is relevant not only to our basic understanding of disparities related to SES, but may also have relevance for the timing or nature of interventions targeting attention skills (Neville et al., 2013; Posner et al., 2015; Tang \& Posner, 2009). A better understanding of the causes of increased distractibility is crucial to improve rehabilitation or training programs to boost attention, in either an applied or clinical approach. 


\section{References}

Aston-Jones, G., \& Cohen, J. D. (2005). An integrative theory of locus coeruleusnorepinephrine function: Adaptive gain and optimal performance. Annual Review of Neuroscience, 28, 403-450. https://doi.org/10.1146/annurev.neuro.28.061604.135709

Auger, N., Lo, E., Cantinotti, M., \& O'Loughlin, J. (2010). Impulsivity and socio-economic status interact to increase the risk of gambling onset among youth. Addiction (Abingdon, England), 105(12), 2176-2183. https://doi.org/10.1111/j.13600443.2010.03100.x

Barratt, E. S., \& Patton, J. H. (1983). Impulsivity: Cognitive, behavioral, and psycholophysiological correlates. In M. Zuckerman (Ed.), Biological bases of sensation seeking, impulsivity and anxiety. (Hillsdale, NJ: Lawrence Erlbaum Associates., p. 77-122).

Bates, D., Mächler, M., Bolker, B., \& Walker, S. (2015). Fitting Linear Mixed-Effects Models Using Ime4. Journal of Statistical Software, 67(1), 1-48. https://doi.org/10.18637/jss.v067.i01

Best, J. R., \& Miller, P. H. (2010). A Developmental Perspective on Executive Function. Child development, 81(6), 1641-1660. https://doi.org/10.1111/j.14678624.2010.01499.x

Betts, J., McKay, J., Maruff, P., \& Anderson, V. (2006). The development of sustained attention in children: The effect of age and task load. Child Neuropsychology: $A$ Journal on Normal and Abnormal Development in Childhood and Adolescence, 12(3), 205-221. https://doi.org/10.1080/09297040500488522

Bidet-Caulet, A., Bottemanne, L., Fonteneau, C., Giard, M.-H., \& Bertrand, O. (2015a). Brain dynamics of distractibility: Interaction between top-down and bottom-up mechanisms of auditory attention. Brain Topography, 28(3), 423-436. https://doi.org/10.1007/s10548-014-0354-X

Bidet-Caulet, A., Bottemanne, L., Fonteneau, C., Giard, M.-H., \& Bertrand, O. (2015b). Brain Dynamics of Distractibility: Interaction Between Top-Down and Bottom-Up Mechanisms of Auditory Attention. Brain Topography, 28(3), 423-436. https://doi.org/10.1007/s10548-014-0354-x

Blakemore, S.-J., \& Choudhury, S. (2006). Development of the adolescent brain: Implications for executive function and social cognition. Journal of Child Psychology and Psychiatry, and Allied Disciplines, 47(3-4), 296-312. https://doi.org/10.1111/j.1469-7610.2006.01611.x

Booth, J. R., Burman, D. D., Meyer, J. R., Lei, Z., Trommer, B. L., Davenport, N. D., Li, W., Parrish, T. B., Gitelman, D. R., \& Mesulam, M. M. (2003). Neural development of selective attention and response inhibition. Neurolmage, 20(2), 737-751. https://doi.org/10.1016/S1053-8119(03)00404-X

Botvinick, M. M., Cohen, J. D., \& Carter, C. S. (2004). Conflict monitoring and anterior cingulate cortex: An update. Trends in Cognitive Sciences, 8(12), 539-546. https://doi.org/10.1016/j.tics.2004.10.003

Brandes-Aitken, A., Braren, S., Swingler, M., Voegtline, K., \& Blair, C. (2019a). Sustained attention in infancy: A foundation for the development of multiple aspects of self- 
regulation for children in poverty. Journal of Experimental Child Psychology, 184, 192-209. https://doi.org/10.1016/j.jecp.2019.04.006

Brandes-Aitken, A., Braren, S., Swingler, M., Voegtline, K., \& Blair, C. (2019b). Sustained attention in infancy: A foundation for the development of multiple aspects of selfregulation for children in poverty. Journal of Experimental Child Psychology, 184, 192-209. https://doi.org/10.1016/j.jecp.2019.04.006

Broadbent, D. E. (1958). Perception and communication (p. v, 340). Pergamon Press. https://doi.org/10.1037/10037-000

Brown, T. T., \& Jernigan, T. L. (2012). Brain development during the preschool years. Neuropsychology review, 22(4), 313-333. https://doi.org/10.1007/s11065-0129214-1

Carver, A. C., Livesey, D. J., \& Charles, M. (2001). Age related changes in inhibitory control as measured by stop signal task performance. The International Journal of Neuroscience, 107(1-2), 43-61. https://doi.org/10.3109/00207450109149756

Casey, B. J., Galvan, A., \& Hare, T. A. (2005). Changes in cerebral functional organization during cognitive development. Current Opinion in Neurobiology, 15(2), 239-244. https://doi.org/10.1016/j.conb.2005.03.012

Checa, P., Castellanos, M. C., Abundis-Gutiérrez, A., \& Rosario Rueda, M. (2014). Development of neural mechanisms of conflict and error processing during childhood: Implications for self-regulation. Frontiers in Psychology, 5. https://doi.org/10.3389/fpsyg.2014.00326

Clayton, M. S., Yeung, N., \& Cohen Kadosh, R. (2015). The roles of cortical oscillations in sustained attention. Trends in Cognitive Sciences, 19(4), 188-195. https://doi.org/10.1016/j.tics.2015.02.004

Coch, D., Sanders, L. D., \& Neville, H. J. (2005). An event-related potential study of selective auditory attention in children and adults. Journal of Cognitive Neuroscience, 17(4), 605-622. https://doi.org/10.1162/0898929053467631

Colombo, J. (2001). The development of visual attention in infancy. Annual Review of Psychology, 52, 337-367. https://doi.org/10.1146/annurev.psych.52.1.337

Commodari, E. (2016). Voluntary Attentional Orienting in Schoolchildren: How Visual Orienting Skills Change During Primary School. Perceptual and Motor Skills, 122(3), 855-870. https://doi.org/10.1177/0031512516652034

Conners, C. K. (2001). Conners' Kiddie Continuous Performance Test (K-CPT). North Tonawanda: Multi-Health Systems, Inc.

Corbetta, M., Patel, G., \& Shulman, G. L. (2008). The reorienting system of the human brain: From environment to theory of mind. Neuron, 58(3), 306-324. https://doi.org/10.1016/j.neuron.2008.04.017

Corbetta, M., \& Shulman, G. L. (2002). Control of goal-directed and stimulus-driven attention in the brain. Nature Reviews. Neuroscience, 3(3), 201-215. https://doi.org/10.1038/nrn755

D’Angiulli, A., Herdman, A., Stapells, D., \& Hertzman, C. (2008). Children's event-related potentials of auditory selective attention vary with their socioeconomic status. Neuropsychology, 22(3), 293-300. https://doi.org/10.1037/0894-4105.22.3.293

Deutsch, J. A., \& Deutsch, D. (1963). Attention: Some theoretical considerations. Psychological Review, 70(1), 80-90. https://doi.org/10.1037/h0039515 
Diagnostic and statistical manual of mental disorders : DSM-5 $5^{T M}$, 5th ed. (2013). American Psychiatric Publishing, Inc. https://doi.org/10.1176/appi.books.9780890425596

Diamond, A. (2013). Executive functions. Annual Review of Psychology, 64, 135-168. https://doi.org/10.1146/annurev-psych-113011-143750

Duncan, M. J., Smith, M., Bryant, E., Eyre, E., Cook, K., Hankey, J., Tallis, J., Clarke, N., \& Jones, M. V. (2016). Effects of increasing and decreasing physiological arousal on anticipation timing performance during competition and practice. European Journal of Sport 27-35. https://doi.org/10.1080/17461391.2014.979248

EIShafei, H. A., Bouet, R., Bertrand, O., \& Bidet-Caulet, A. (2018). Two Sides of the Same Coin: Distinct Sub-Bands in the a Rhythm Reflect Facilitation and Suppression Mechanisms during Auditory Anticipatory Attention. ENeuro, 5(4). https://doi.org/10.1523/ENEURO.0141-18.2018

EIShafei, H. A., Fornoni, L., Bertrand, O., \& Bidet-Caulet, A. (2018). Not Just A Number : Age-Related Modulations of Oscillatory Patterns Underlying Top-Down and Bottom-Up Attention. BioRxiv, 496117. https://doi.org/10.1101/496117

EIShafei, H. A., Fornoni, L., Masson, R., Bertrand, O., \& Bidet-Caulet, A. (2019). What's in Your Gamma? Activation of the Ventral Fronto-Parietal Attentional Network in Response to Distracting Sounds. Cerebral Cortex (New York, N.Y.: 1991). https://doi.org/10.1093/cercor/bhz119

Escera, C., Alho, K., Schröger, E., \& Winkler, I. (2000). Involuntary attention and distractibility as evaluated with event-related brain potentials. Audiology \& NeuroOtology, 5(3-4), 151-166. https://doi.org/13877

Esterman, M., \& Rothlein, D. (2019). Models of sustained attention. Current Opinion in Psychology, 29, 174-180. https://doi.org/10.1016/j.copsyc.2019.03.005

Eysenck, H. J., \& Eysenck, M. W. (1985). Personality and individual differences : A Natural Science Approach (New York: Plenum).

Eysenck, M. (1982). Attention and Arousal : Cognition and Performance. Springer-Verlag. https://www.springer.com/gp/book/9783642683923

Farah, M. J. (2017). The Neuroscience of Socioeconomic Status : Correlates, Causes, and Consequences. Neuron, 96(1), 56-71. https://doi.org/10.1016/j.neuron.2017.08.034

Farah, M. J., Shera, D. M., Savage, J. H., Betancourt, L., Giannetta, J. M., Brodsky, N. L., Malmud, E. K., \& Hurt, H. (2006). Childhood poverty: Specific associations with neurocognitive development. Brain Research, 1110(1), 166-174. https://doi.org/10.1016/j.brainres.2006.06.072

Farrant, K., \& Uddin, L. Q. (2015). Asymmetric development of dorsal and ventral attention networks in the human brain. Developmental Cognitive Neuroscience, 12, 165-174. https://doi.org/10.1016/j.dcn.2015.02.001

Federico, F., Marotta, A., Martella, D., \& Casagrande, M. (2017). Development in attention functions and social processing: Evidence from the Attention Network Test. The British Journal of Developmental Psychology, 35(2), 169-185. https://doi.org/10.1111/bjdp.12154

Fox, J., \& Weisberg, S. (2018). An R Companion to Applied Regression. SAGE Publications. 
Giuliano, R. J., Karns, C. M., Roos, L. E., Bell, T. A., Petersen, S., Skowron, E. A., Neville, H. J., \& Pakulak, E. (2018). Effects of early adversity on neural mechanisms of distractor suppression are mediated by sympathetic nervous system activity in preschool-aged children. Developmental Psychology, 54(9), 1674-1686. https://doi.org/10.1037/dev0000499

Gogtay, N., Giedd, J. N., Lusk, L., Hayashi, K. M., Greenstein, D., Vaituzis, A. C., Nugent, T. F., Herman, D. H., Clasen, L. S., Toga, A. W., Rapoport, J. L., \& Thompson, P. M. (2004). Dynamic mapping of human cortical development during childhood through early adulthood. Proceedings of the National Academy of Sciences of the United States of America, 101(21), 8174-8179. https://doi.org/10.1073/pnas.0402680101

Graziano, P. A., Calkins, S. D., \& Keane, S. P. (2011). Sustained Attention Development during the Toddlerhood to Preschool Period: Associations with Toddlers' Emotion Regulation Strategies and Maternal Behavior. Infant and child development, 20(6), 389-408. https://doi.org/10.1002/icd.731

Hampton Wray, A., Stevens, C., Pakulak, E., Isbell, E., Bell, T., \& Neville, H. (2017). Development of selective attention in preschool-age children from lower socioeconomic status backgrounds. Developmental Cognitive Neuroscience, 26, 101-111. https://doi.org/10.1016/j.den.2017.06.006

Helfrich, R. F., Fiebelkorn, I. C., Szczepanski, S. M., Lin, J. J., Parvizi, J., Knight, R. T., \& Kastner, S. (2018). Neural Mechanisms of Sustained Attention Are Rhythmic. Neuron, 99(4), 854-865.e5. https://doi.org/10.1016/j.neuron.2018.07.032

Hernes, K. G., Mørkrid, L., Fremming, A., Ødegården, S., Martinsen, Ø. G., \& Storm, H. (2002). Skin conductance changes during the first year of life in full-term infants. Pediatric Research, 52(6), 837-843. https://doi.org/10.1203/00006450-20021200000005

Houston, R. J., \& Stanford, M. S. (2001). Mid-latency evoked potentials in self-reported impulsive aggression. International Journal of Psychophysiology: Official Journal of the International Organization of Psychophysiology, 40(1), 1-15.

Howard, S. J., Johnson, J., \& Pascual-Leone, J. (2014). Clarifying inhibitory control: Diversity and development of attentional inhibition. Cognitive Development, 31, 1-21. https://doi.org/10.1016/j.cogdev.2014.03.001

Howells, F. M., Stein, D. J., \& Russell, V. A. (2012). Synergistic tonic and phasic activity of the locus coeruleus norepinephrine (LC-NE) arousal system is required for optimal attentional performance. Metabolic Brain Disease, 27(3), 267-274. https://doi.org/10.1007/s11011-012-9287-9

Hoyer, R. S., Elshafei, H., Hemmerlin, J., Bouet, R., \& Bidet-Caulet, A. (2019). Why are children so distractible? Development of attentional capacities and phasic arousal from childhood to adulthood. BioRxiv, 747527. https://doi.org/10.1101/747527

Hoyer, Roxane S., Elshafei, H., Hemmerlin, J., Bouet, R., \& Bidet-Caulet, A. (2021). Why are children so distractible? Development of attentional capacities and motor control from childhood to adulthood. BioRxiv, 747527. https://doi.org/10.1101/747527

Hrabok, M., Kerns, K. A., \& Müller, U. (2007). The vigilance, orienting, and executive attention networks in 4-year-old children. Child Neuropsychology: A Journal on 
Normal and Abnormal Development in Childhood and Adolescence, 13(5), 408-421. https://doi.org/10.1080/13825580600977224

Johnson, M. H., Posner, M. I., \& Rothbart, M. K. (1991). Components of visual orienting in early infancy : Contingency learning, anticipatory looking, and disengaging. Journal of Cognitive Neuroscience, 3(4), 335-344. https://doi.org/10.1162/jocn.1991.3.4.335

Kahneman, D. (1973). Attention and effort. Prentice-Hall.

Kanaka, N., Matsuda, T., Tomimoto, Y., Noda, Y., Matsushima, E., Matsuura, M., \& Kojima, T. (2008). Measurement of development of cognitive and attention functions in children using continuous performance test. Psychiatry and Clinical Neurosciences, 62(2), 135-141. https://doi.org/10.1111/j.1440-1819.2008.01746.x

Karns, C. M., Isbell, E., Giuliano, R. J., \& Neville, H. J. (2015). Auditory attention in childhood and adolescence: An event-related potential study of spatial selective attention to one of two simultaneous stories. Developmental Cognitive Neuroscience, 13, 53-67. https://doi.org/10.1016/j.dcn.2015.03.001

Keil, A., Gruber, T., Müller, M. M., Moratti, S., Stolarova, M., Bradley, M. M., \& Lang, P. J. (2003). Early modulation of visual perception by emotional arousal : Evidence from steady-state visual evoked brain potentials. Cognitive, Affective, \& Behavioral Neuroscience, 3(3), 195-206. https://doi.org/10.3758/CABN.3.3.195

Landau, A. N., \& Fries, P. (2012). Attention samples stimuli rhythmically. Current Biology: $C B, 22(11), 1000-1004$. https://doi.org/10.1016/j.cub.2012.03.054

Lansink, J. M., \& Richards, J. E. (1997). Heart rate and behavioral measures of attention in six-, nine-, and twelve-month-old infants during object exploration. Child Development, 68(4), 610-620.

Lawson, G. M., Duda, J. T., Avants, B. B., Wu, J., \& Farah, M. J. (2013). Associations between Children's Socioeconomic Status and Prefrontal Cortical Thickness. Developmental science, 16(5), 641-652. https://doi.org/10.1111/desc.12096

Lee, M. D., \& Wagenmakers, E.-J. (2013). Bayesian cognitive modeling: A practical course. Cambridge University Press. https://doi.org/10.1017/CBO9781139087759

Lenartowicz, A., Simpson, G. V., \& Cohen, M. S. (2013). Perspective: Causes and functional significance of temporal variations in attention control. Frontiers in Human Neuroscience, 7, 381. https://doi.org/10.3389/fnhum.2013.00381

Lin, C. C., Hsiao, C. K., \& Chen, W. J. (1999). Development of sustained attention assessed using the continuous performance test among children 6-15 years of age. Journal of Abnormal Child Psychology, 27(5), 403-412.

Lundwall, R. A., Sgro, J. F., \& Fanger, J. (2018). Response time scores on a reflexive attention task predict a child's inattention score from a parent report. PLOS ONE, 13(1). https://doi.org/10.1371/journal.pone.0190724

Mahone, E. M., Pillion, J. P., \& Hiemenz, J. R. (2001). Initial development of an auditory continuous performance test for preschoolers. Journal of Attention Disorders, 5(2), 93-106. https://doi.org/10.1177/108705470100500203

Mansouri, F. A., Egner, T., \& Buckley, M. J. (2017). Monitoring Demands for Executive Control: Shared Functions between Human and Nonhuman Primates. Trends in Neurosciences, 40(1), 15-27. https://doi.org/10.1016/j.tins.2016.11.001 
Masson, R., \& Bidet-Caulet, A. (2019). Fronto-central P3a to distracting sounds: An index of their arousing properties. Neurolmage, 185, 164-180. https://doi.org/10.1016/j.neuroimage.2018.10.041

Matuschek, H., Kliegl, R., Vasishth, S., Baayen, H., \& Bates, D. (2017). Balancing Type I error and power in linear mixed models. Journal of Memory and Language, 94, 305-315. https://doi.org/10.1016/j.jml.2017.01.001

Max, C., Widmann, A., Kotz, S. A., Schröger, E., \& Wetzel, N. (2015a). Distraction by emotional sounds: Disentangling arousal benefits and orienting costs. Emotion, 15(4), 428-437. https://doi.org/10.1037/a0039041

Max, C., Widmann, A., Kotz, S. A., Schröger, E., \& Wetzel, N. (2015b). Distraction by emotional sounds: Disentangling arousal benefits and orienting costs. Emotion (Washington, D.C.), 15(4), 428-437. https://doi.org/10.1037/a0039041

McEwen, B. S., \& Gianaros, P. J. (2010). Central role of the brain in stress and adaptation : Links to socioeconomic status, health, and disease. Annals of the New York Academy of Sciences, 1186, 190-222. https://doi.org/10.1111/j.17496632.2009.05331.x

McEwen, C. A., \& McEwen, B. S. (2017). Social Structure, Adversity, Toxic Stress, and Intergenerational Poverty : An Early Childhood Model. Annual Review of Sociology, 43(1), 445-472. https://doi.org/10.1146/annurev-soc-060116-053252

McGoey, K. E., DuPaul, G. J., Haley, E., \& Shelton, T. L. (2007). Parent and Teacher Ratings of Attention-Deficit/Hyperactivity Disorder in Preschool : The ADHD Rating Scale-IV Preschool Version. Journal of Psychopathology and Behavioral Assessment, 29(4), 269-276. https://doi.org/10.1007/s10862-007-9048-y

Meade, E. R. (1981). Impulse Control and Cognitive Functioning in Lowerand Middle-SES Children: A Developmental Study. Merrill-Palmer Quarterly of Behavior and Development, 27(3), 271-285. JSTOR.

Mezzacappa, E. (2004a). Alerting, Orienting, and Executive Attention: Developmental Properties and Sociodemographic Correlates in an Epidemiological Sample of Young, Urban Children. Child Development, 75(5), 1373-1386. https://doi.org/10.1111/j.1467-8624.2004.00746.x

Mezzacappa, E. (2004b). Alerting, orienting, and executive attention: Developmental properties and sociodemographic correlates in an epidemiological sample of young, urban children. Child Development, 75(5), 1373-1386. https://doi.org/10.1111/j.1467-8624.2004.00746.x

Mullane, J. C., Lawrence, M. A., Corkum, P. V., Klein, R. M., \& McLaughlin, E. N. (2016). The development of and interaction among alerting, orienting, and executive attention in children. Child Neuropsychology, 22(2), 155-176. https://doi.org/10.1080/09297049.2014.981252

Näätänen, R. (1992a). Attention and brain function. Lawrence Erlbaum Associates, Inc.

Näätänen, R. (1992b). Attention and brain function (p. xx, 494). Lawrence Erlbaum Associates, Inc.

Neville, H. J., Stevens, C., Pakulak, E., Bell, T. A., Fanning, J., Klein, S., \& Isbell, E. (2013). Family-based training program improves brain function, cognition, and behavior in lower socioeconomic status preschoolers. Proceedings of the National Academy of Sciences, 110(29), 12138-12143. https://doi.org/10.1073/pnas.1304437110 
Noble, K. G., Houston, S. M., Kan, E., \& Sowell, E. R. (2012). Neural correlates of socioeconomic status in the developing human brain. Developmental Science, 15(4), 516-527. https://doi.org/10.1111/j.1467-7687.2012.01147.x

Noble, W., Jensen, N. S., Naylor, G., Bhullar, N., \& Akeroyd, M. A. (2013). A short form of the Speech, Spatial and Qualities of Hearing scale suitable for clinical use: The SSQ12. International journal of audiology, 52(6), 409-412. https://doi.org/10.3109/14992027.2013.781278

Oakes, L. M., \& Tellinghuisen, D. J. (1994). Examining in infancy: Does it reflect active processing? Developmental Psychology, 30(5), 748-756. https://doi.org/10.1037/0012-1649.30.5.748

Oken, B. S., Salinsky, M. C., \& Elsas, S. M. (2006). Vigilance, alertness, or sustained attention : Physiological basis and measurement. Clinical Neurophysiology, 117(9), 1885-1901. https://doi.org/10.1016/j.clinph.2006.01.017

Olesen, P. J., Macoveanu, J., Tegnér, J., \& Klingberg, T. (2007). Brain activity related to working memory and distraction in children and adults. Cerebral Cortex (New York, N.Y.: 1991), 17(5), 1047-1054. https://doi.org/10.1093/cercor/bhl014

Pakulak, E., Stevens, C., \& Neville, H. (2018). Neuro-, Cardio-, and Immunoplasticity: Effects of Early Adversity (SSRN Scholarly Paper ID 3121914). Social Science Research Network. https://doi.org/10.1146/annurev-psych-010416-044115

Palva, J. M., Zhigalov, A., Hirvonen, J., Korhonen, O., Linkenkaer-Hansen, K., \& Palva, S. (2013). Neuronal long-range temporal correlations and avalanche dynamics are correlated with behavioral scaling laws. Proceedings of the National Academy of Sciences of the United States of America, 110(9), 3585-3590. https://doi.org/10.1073/pnas.1216855110

Parasuraman, R., Nestor, P. G., \& Greenwood, P. (1989). Sustained-attention capacity in young and older adults. Psychology and Aging, 4(3), 339-345. https://doi.org/10.1037/0882-7974.4.3.339

Parmentier, F. B. R., \& Andrés, P. (2010). The Involuntary Capture of Attention by Sound: Novelty and Postnovelty Distraction in Young and Older Adults. Experimental Psychology, 57(1), 68-76. https://doi.org/10.1027/1618-3169/a000009

Petersen, S. E., \& Posner, M. I. (2012). The Attention System of the Human Brain : 20 Years After. Annual review of neuroscience, 35, 73-89. https://doi.org/10.1146/annurev-neuro-062111-150525

Petton, M., Perrone-Bertolotti, M., Mac-Auliffe, D., Bertrand, O., Aguera, P.-E., Sipp, F., Batthacharjee, M., Isnard, J., Minotti, L., Rheims, S., Kahane, P., Herbillon, V., \& Lachaux, J.-P. (2018). BLAST: A short computerized test to measure the ability to stay on task. Normative behavioral data and detailed cortical dynamics. BioRxiv, 498691. https://doi.org/10.1101/498691

Posner, M. I. (1980). Orienting of attention. Quarterly Journal of Experimental Psychology, 32(1), 3-25. https://doi.org/10.1080/00335558008248231

Posner, M. I. (2012). Attentional Networks and Consciousness. Frontiers in Psychology, 3. https://doi.org/10.3389/fpsyg.2012.00064

Posner, M. I., Rothbart, M. K., Sheese, B. E., \& Voelker, P. (2014). Developing Attention: Behavioral and Brain Mechanisms [Review Article]. Advances in Neuroscience; Hindawi. https://doi.org/10.1155/2014/405094 
Posner, M. I., Rothbart, M. K., \& Tang, Y.-Y. (2015). Enhancing attention through training. Current Opinion in Behavioral Sciences, 4, 1-5. https://doi.org/10.1016/j.cobeha.2014.12.008

Posner, M., \& Petersen, S. (1990). The Attention System of the Human Brain. Annual review of neuroscience, 25-42. https://doi.org/10.1146/annurev.ne.13.030190.000325

Posner, M., Rothbart, M., \& Rueda, M. (2014). Developing attention and self-regulation in childhood (p. 541-569).

Reis Lellis, V. R., de Castro Mariani, M. M., de Fátima Ribeiro, A., Cantiere, C. N., Veloz Teixeira, M. C. T., \& Rodrigues Carreiro, L. R. (2013). Voluntary and automatic orienting of attention during childhood development. Psychology \& Neuroscience, 6(1), 15-21. https://doi.org/10.3922/j.psns.2013.1.04

Reynolds, G. D., \& Romano, A. C. (2016). The Development of Attention Systems and Working Memory in Infancy. Frontiers in Systems Neuroscience, 10. https://doi.org/10.3389/fnsys.2016.00015

Riccio, C. A., Hynd, G. W., Cohen, M. J., Hall, J., \& Molt, L. (1994). Comorbidity of central auditory processing disorder and attention-deficit hyperactivity disorder. Journal of the American Academy of Child \& Adolescent Psychiatry, 33(6), 849-857.

Richards, J. E., \& Casey, B. J. (1991). Heart rate variability during attention phases in young infants. Psychophysiology, 28(1), 43-53. https://doi.org/10.1111/j.14698986.1991.tb03385.x

Ross-Sheehy, S., Schneegans, S., \& Spencer, J. P. (2015a). The Infant Orienting With Attention task: Assessing the neural basis of spatial attention in infancy. Infancy: the official journal of the International Society on Infant Studies, 20(5), 467-506. https://doi.org/10.1111/infa.12087

Ross-Sheehy, S., Schneegans, S., \& Spencer, J. P. (2015b). The Infant Orienting With Attention task: Assessing the neural basis of spatial attention in infancy. Infancy: the official journal of the International Society on Infant Studies, 20(5), 467-506. https://doi.org/10.1111/infa.12087

Rothbart, M. K., Sheese, B. E., Rueda, M. R., \& Posner, M. I. (2011). Developing Mechanisms of Self-Regulation in Early Life. Emotion review, 3(2), 207-213. https://doi.org/10.1177/1754073910387943

Rueda, M. R., Fan, J., McCandliss, B. D., Halparin, J. D., Gruber, D. B., Lercari, L. P., \& Posner, M. I. (2004). Development of attentional networks in childhood. $\begin{array}{lll}\text { Neuropsychologia, } & 42(8), & 1029-1040 .\end{array}$ https://doi.org/10.1016/j.neuropsychologia.2003.12.012

Ruff, H. A., \& Capozzoli, M. C. (2003). Development of attention and distractibility in the first 4 years of life. Developmental Psychology, 39(5), 877-890. https://doi.org/10.1037/0012-1649.39.5.877

SanMiguel, I., Linden, D., \& Escera, C. (2010). Attention capture by novel sounds: Distraction versus facilitation. European Journal of Cognitive Psychology, 22(4), 481-515. https://doi.org/10.1080/09541440902930994

Slobodin, O., Cassuto, H., \& Berger, I. (2015). Age-Related Changes in Distractibility: Developmental Trajectory of Sustained Attention in ADHD: Journal of Attention Disorders. https://doi.org/10.1177/1087054715575066 
Stanford, M. S., Mathias, C. W., Dougherty, D. M., Lake, S. L., Anderson, N. E., \& Patton, J. H. (2009). Fifty years of the Barratt Impulsiveness Scale : An update and review. Personality and Individual Differences, 47(5), 385-395. https://doi.org/10.1016/j.paid.2009.04.008

Stevens, C., \& Bavelier, D. (2012). The role of selective attention on academic foundations: A cognitive neuroscience perspective. Developmental Cognitive Neuroscience, 2 Suppl 1, S30-48. https://doi.org/10.1016/j.dcn.2011.11.001

Stevens, C., Lauinger, B., \& Neville, H. (2009). Differences in the neural mechanisms of selective attention in children from different socioeconomic backgrounds: An event-related brain potential study. Developmental Science, 12(4), 634-646. https://doi.org/10.1111/j.1467-7687.2009.00807.x

Tang, Y.-Y., \& Posner, M. I. (2009). Attention training and attention state training. Trends in Cognitive Sciences, 13(5), 222-227. https://doi.org/10.1016/j.tics.2009.01.009

Tao, T., Wang, L., Fan, C., \& Gao, W. (2014). Development of self-control in children aged 3 to 9 years: Perspective from a dual-systems model. Scientific Reports, 4. https://doi.org/10.1038/srep07272

Thillay, A., Roux, S., Gissot, V., Carteau-Martin, I., Knight, R. T., Bonnet-Brilhault, F., \& Bidet-Caulet, A. (2015). Sustained attention and prediction: Distinct brain maturation trajectories during adolescence. Frontiers in Human Neuroscience, 9. https://doi.org/10.3389/fnhum.2015.00519

Tillman, C. M., Thorell, L. B., Brocki, K. C., \& Bohlin, G. (2007). Motor Response Inhibition and Execution in the Stop-Signal Task: Development and Relation to ADHD Behaviors. Child Neuropsychology, 14(1), 42-59. https://doi.org/10.1080/09297040701249020

Toga, A. W., Thompson, P. M., \& Sowell, E. R. (2006). Mapping brain maturation. Trends in Neurosciences, 29(3), 148-159. https://doi.org/10.1016/j.tins.2006.01.007

Treisman, A. M., \& Riley, J. G. (1969). Is selective attention selective perception or selective response? A further test. Journal of Experimental Psychology, 79(1, Pt.1), 27-34. https://doi.org/10.1037/h0026890

Unsworth, N., \& Robison, M. K. (2017). A locus coeruleus-norepinephrine account of individual differences in working memory capacity and attention control. Psychonomic Bulletin \& Review, 24(4), 1282-1311. https://doi.org/10.3758/s13423016-1220-5

Ursache, A., \& Noble, K. G. (2016). Neurocognitive development in socioeconomic context: Multiple mechanisms and implications for measuring socioeconomic status. Psychophysiology, 53(1), 71-82. https://doi.org/10.1111/psyp.12547

van den Wildenberg, W. P., \& Crone, E. A. (2005). Development of response inhibition and decision-making across childhood: A cognitive neuroscience perspective. Focus on child psychology research, 23-42.

Wainwright, A., \& Bryson, S. E. (2002). The development of exogenous orienting: Mechanisms of control. Journal of Experimental Child Psychology, 82(2), 141-155. https://doi.org/10.1016/s0022-0965(02)00002-4

Wetzel, N., Buttelmann, D., Schieler, A., \& Widmann, A. (2015). Infant and adult pupil dilation in response to unexpected sounds. Developmental psychobiology, 58. https://doi.org/10.1002/dev.21377 
Wetzel, N., Scharf, F., \& Widmann, A. (2018). Can't Ignore-Distraction by Task-Irrelevant Sounds in Early and Middle Childhood. Child Development. https://doi.org/10.1111/cdev.13109

Wetzel, N., \& Schröger, E. (2007). Cognitive control of involuntary attention and distraction in children and adolescents. Brain Research, 1155, 134-146. https://doi.org/10.1016/j.brainres.2007.04.022

Wetzel, N., \& Schröger, E. (2014). On the development of auditory distraction : A review: Development of auditory distraction. PsyCh Journal, 3(1), 72-91. https://doi.org/10.1002/pchj.49

Wetzel, N., Schröger, E., \& Widmann, A. (2016). Distraction by Novel and Pitch-Deviant $\begin{array}{lllll}\text { Sounds in Children. Frontiers in Psychology, } & 7 .\end{array}$ https://doi.org/10.3389/fpsyg.2016.01949

Wetzel, N., Widmann, A., Berti, S., \& Schröger, E. (2006). The development of involuntary and voluntary attention from childhood to adulthood: A combined behavioral and event-related potential study. Clinical Neurophysiology, 117(10), 2191-2203. https://doi.org/10.1016/j.clinph.2006.06.717

Wetzel, N., Widmann, A., \& Schröger, E. (2012). Distraction and facilitation-two faces of the same coin? Journal of Experimental Psychology: Human Perception and Performance, 38(3), 664-674. https://doi.org/10.1037/a0025856

Wiebe, S. A., Sheffield, T. D., \& Andrews Espy, K. (2012). Separating the fish from the sharks : A longitudinal study of preschool response inhibition. Child Development, 83(4), 1245-1261. https://doi.org/10.1111/j.1467-8624.2012.01765.x

Wright, I., Waterman, M., Prescott, H., \& Murdoch-Eaton, D. (2003). A new Stroop-like measure of inhibitory function development : Typical developmental trends. Journal of Child Psychology and Psychiatry, and Allied Disciplines, 44(4), 561-575.

Yerkes, R. M., \& Dodson, J. D. (1908). The Relation of Strength of Stimulus to Rapidity of Habit Formation. Journal of Comparative Neurology \& Psychology, 18, 459-482. https://doi.org/10.1002/cne.920180503

Zhang, S., Hu, S., Hu, J., Wu, P.-L., Chao, H. H., \& Li, C. R. (2015). Barratt Impulsivity and Neural Regulation of Physiological Arousal. PLoS ONE, 10(6). https://doi.org/10.1371/journal.pone.0129139 


\section{Appendix}

\section{A. Behavioral arousal and distraction effect in the CAT paradigm}

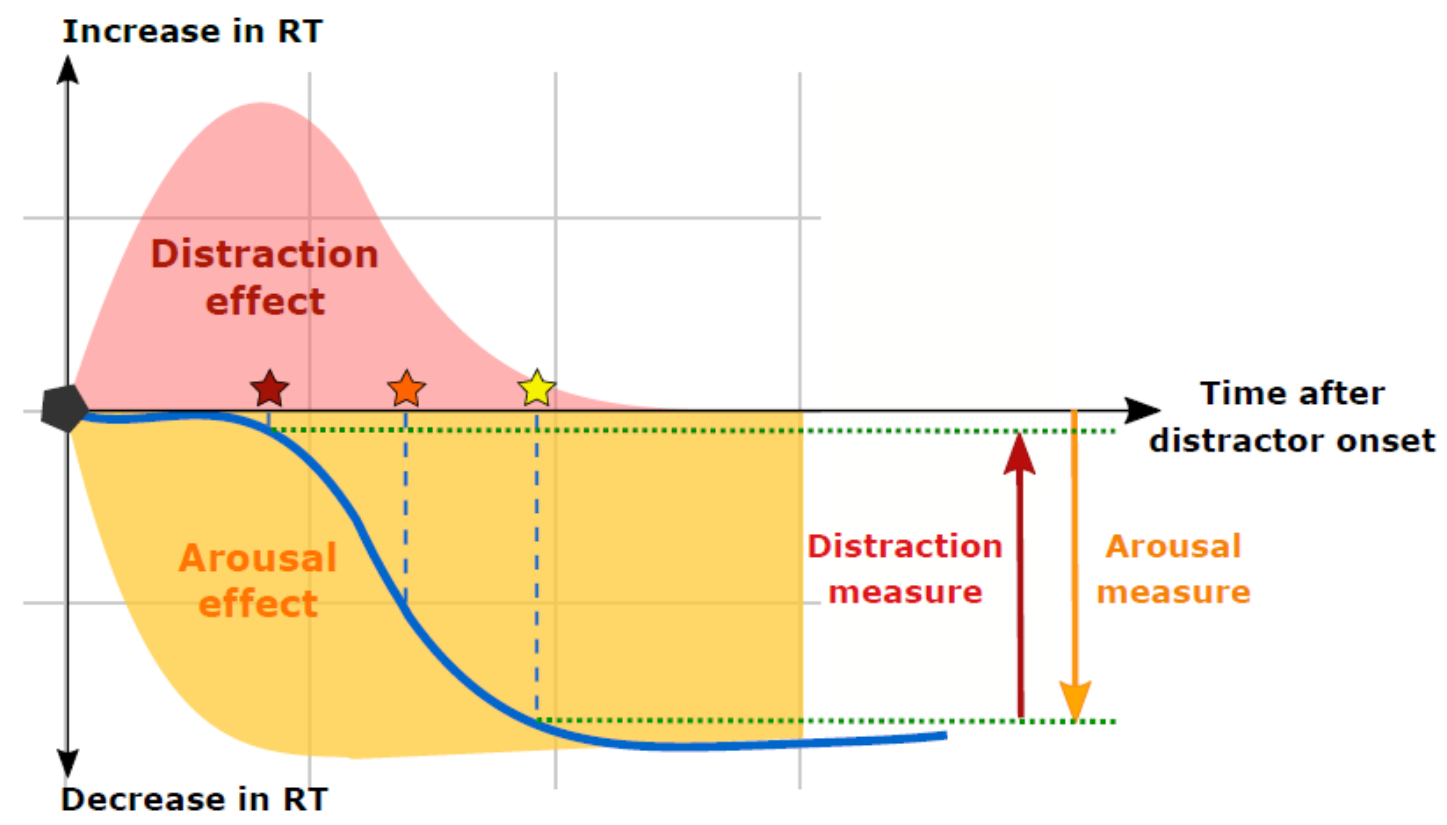

- Resulting effect on reaction time in comparison to the NoDis condition

Distractor onset

Target onset in Dis3 condition (short distractor-target delay)

th Target onset in Dis2 condition (middle distractor-target delay)

¿ Target onset in Dis1 condition (long distractor-target delay)

figure A1. Schematic view of the cost and benefit triggered by distracting sounds. The effect of distracting sound on reaction time (blue line) depends on the distractor-target interval in the task design and results from the combination of the beneficial arousal and detrimental distraction effects.

\section{B. Instructions and illustrations}

\section{Treasure map}

Here you have a treasure map. Do you see the treasure in this map? (find the treasure with the child) You will start here (first island on the left) and then move on the next island until you reach the island with the treasure. To move from your island to another one, you will play a game on this laptop. Each time you finish a game, you will move forward one 
island closer to the treasure. And when you finish all the games and reach the treasure, then you will get to choose a gift from this treasure box!

\section{Competitive Attention Test instructions for preschool-aged children}

In this game you'll really need to pay attention and push the button as fast as you can.

This time you'll see a gray screen with a blue cross in the middle. This cross will disappear and then you'll see a dog. The dog will be either looking right at you or looking to one side.

When the dog is looking right at you, it means that he will soon bark in either in your right ear or in your left ear, but you won't know which one!

But when the dog is looking to the right, he's telling you that he'll soon bark in your right ear. When he's looking to the left, he's telling you that he'll soon bark in your left ear. Does that make sense?

You really have to pay attention to where the dog is pointing because he's telling you where he's going to bark! So he's helping you push the button as fast as you can when he barks. This is the button you push whenever he barks (show button)

Sometimes it's a little harder because when you see the dog you'll hear a bell. Don't click the button when you hear the bell - only when the dog barks! But you still have to click the button when the dog barks, even if it's after the ring. Does that make sense?

When you do a good job of pushing the button fast right after the dog barks, the dog will be happy and you'll see him with his bone in his mouth. It's OK if you make a mistake and click on the bell - you can still click again when the dog barks.

We'll play the game three times, and after each time we'll move closer to the treasure. Do you remember what happens when you get to the treasure? Yes - you get to choose a prize! 
bioRxiv preprint doi: https://doi.org/10.1101/2021.04.06 438161 this version posted April 8, 2021. The copyright holder for this preprint (which was not certified by peer review) is the author/funder, who has granted bioRxiv a license to display the preprint in perpetuity. It is made available under aCC-BY-NC-ND 4.0 International license.

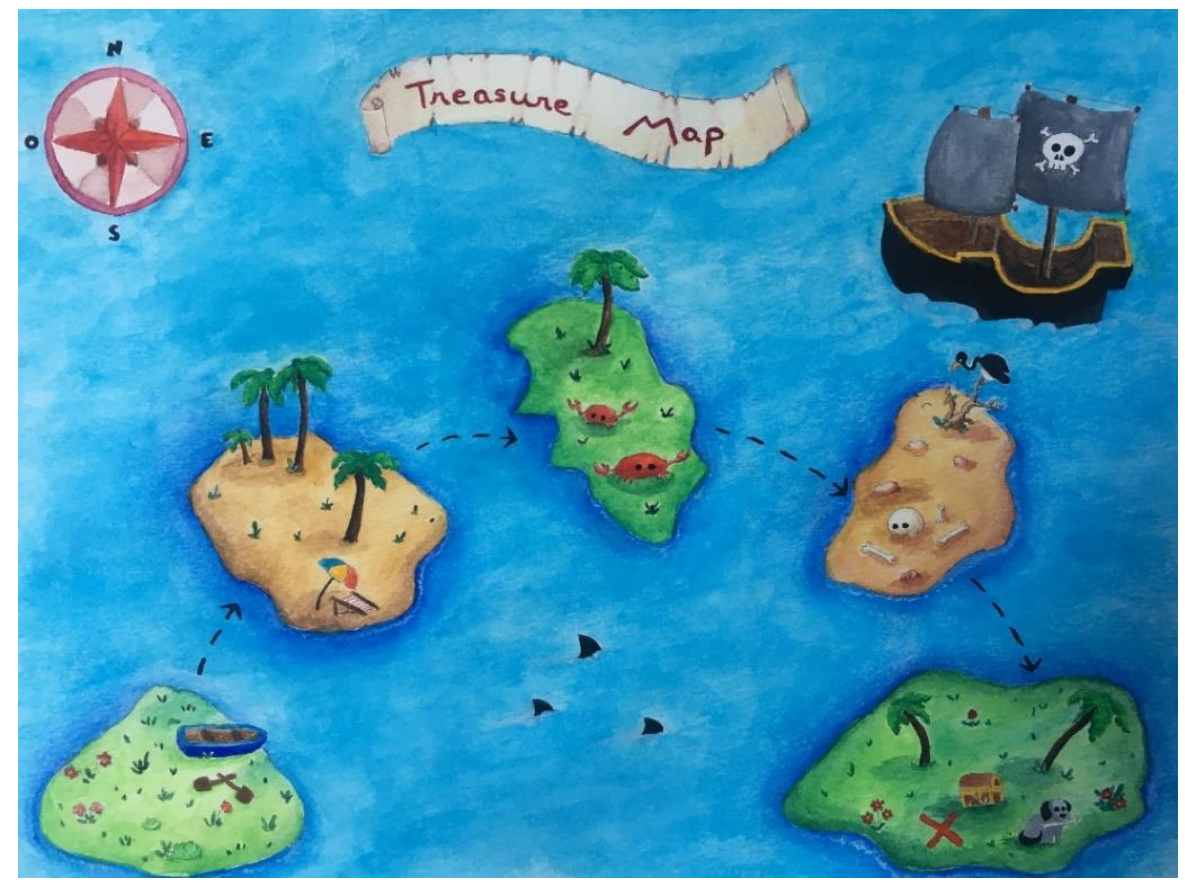

Fig. A2 | Treasure map used to motivate children during testing.

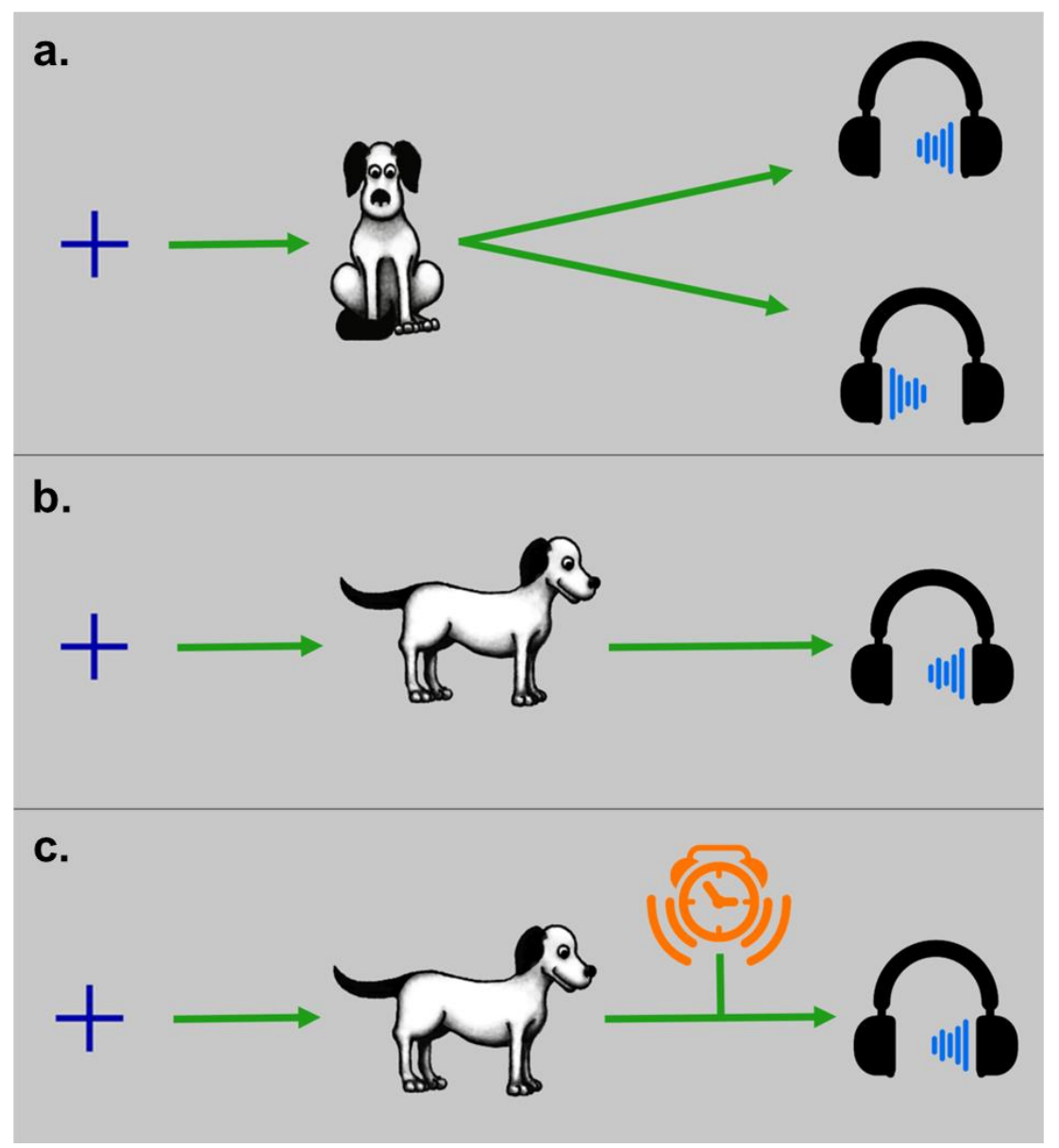

Fig. A3 | Illustration used to depict a) an uninformative NoDis trials, b) an informative NoDis trials and c) a distractor trial 


\section{RT lower limit}

To dissociate anticipated and fast correct behavioral responses, we identified a RT lower threshold (RT lower limit) for correct responses for each age group. We computed the frequency distribution of RT of all trials of all subjects by age range with a $50 \mathrm{~ms}$ step (see Fig. below). We considered the 100 to 500 ms period post target onset and performed ordered-timeline non parametric paired Wilcoxon tests for each age range to determine what lower RT threshold we should consider.

Ordered-timeline paired Wilcoxon tests on RT frequency distributions for every age range indicated that the percentage of responses became significantly larger (threshold: $p$ $<.05)$ from the previous time range during the post target onset period of $400-450 \mathrm{~ms}$ in both the 4 and 5-year-old children. Therefore, the shortest reaction time for a correct response (RT lower limit) was fixed to $400 \mathrm{~ms}$ in preschool-aged children.
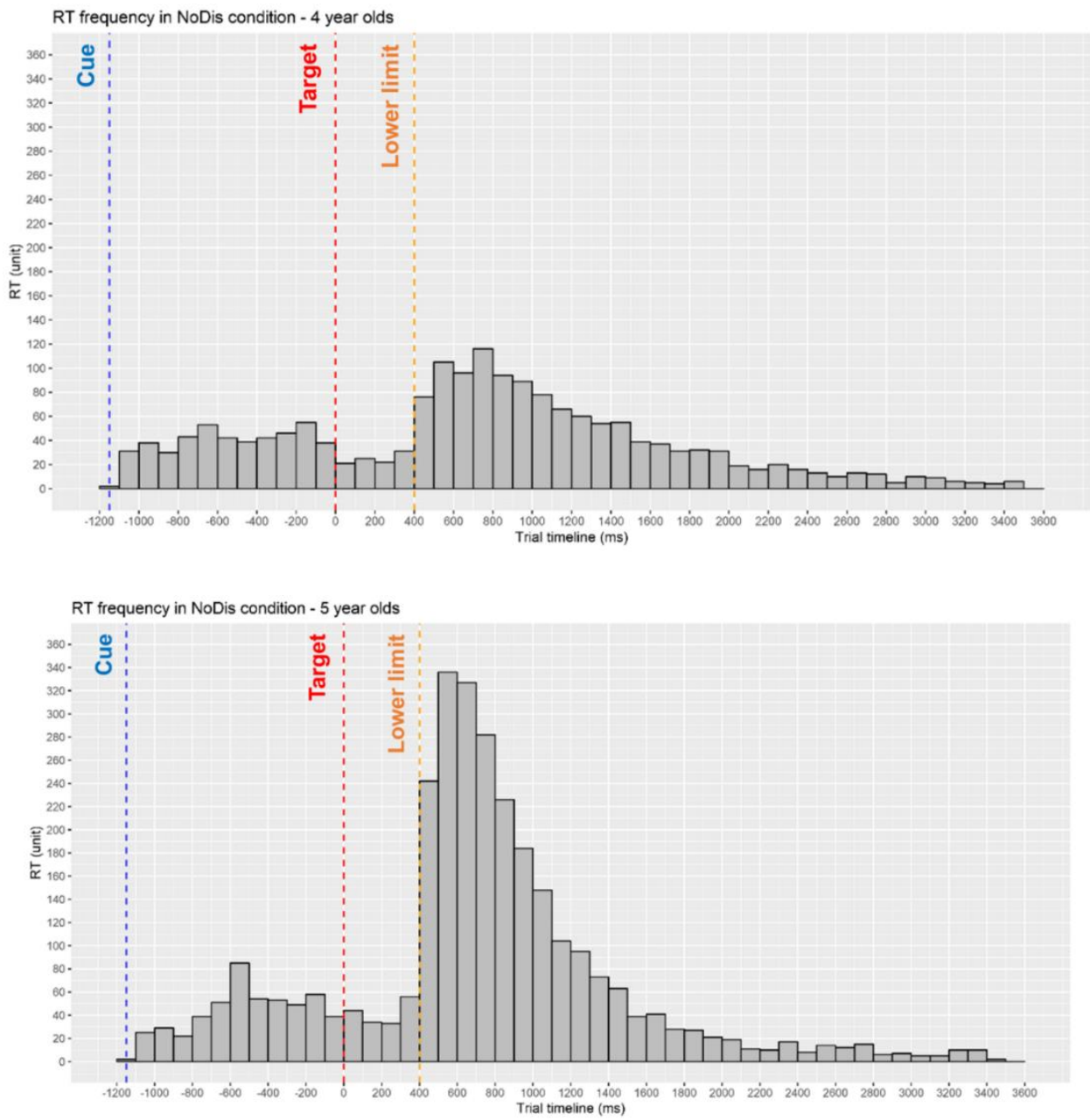

Figure A4. Lower RT limit according to age. Histogram of the number of trials ( $y$ axis) according to the RT in ms ( $x$ axis) in the NoDis condition, across all participants of each age range. The blue dotted line indicates the cue onset; the red dotted line indicates the target onset; finally, the orange dotted line indicates the significant $(p<.05)$ threshold identified using ordered-timeline non-parametric paired Wilcoxon tests. 
bioRxiv preprint doi: https://doi. org/10.1101/2021.04 06 438161· this version posted April 8, 2021. The copyright holder for this preprint (which was not certified by peer review) is the author/funder, who has granted bioRxiv a license to display the preprint in perpetuity. It is made available under aCC-BY-NC-ND 4.0 International license.

\section{Response type categorization}

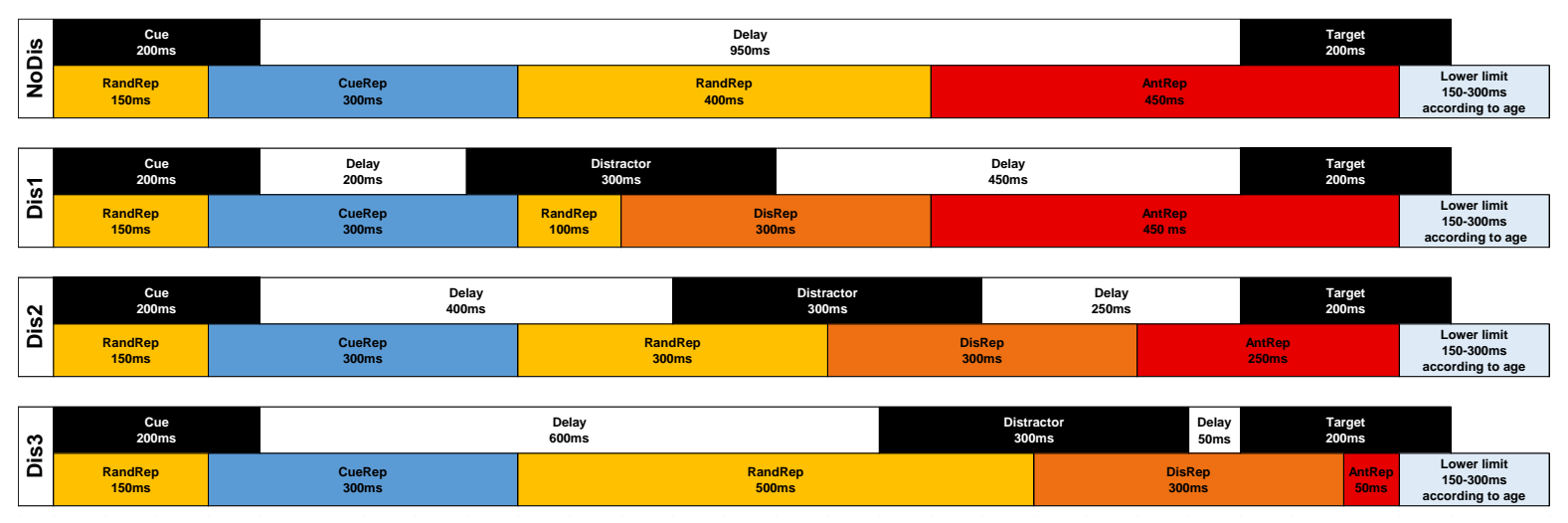

Figure A5. Timeline for the behavioral response categorization during the CAT trials. From top to bottom: NoDis, Dis1, Dis2 and Dis3 conditions. The top row depicts the timing of the task related events (cue, distractor and target); the bottom row shows the category in which the behavioral response is assigned based on timing of response. Abbreviations: Cue responses (CueRep), Responses to distractors (DisRep), anticipated responses (AntRep) and random responses (RandRep). 


\section{E. Details for statistical analyses of RT variability and erroneous responses}

RT SD were log-transformed at the single trial scale to be better fitted to a linear model with Gaussian family distribution, with the fixed factors AGE and SES as between-subject factor and BLOCK (3 levels) as within subject factor.

Response types were fitted to a linear model with binomial distribution without transformation. GLMMs extend the linear mixed model to deal with non-normally distributed data. In particular, GLMMs can handle binary data. In this respect, GLMM analyses consider a number of data points equal to the total number of trials presented during the test, in each subject.

LateRep were fitted to a linear model with binomial distribution without transformation, with fixed factors AGE and SES as between-subject factors and CUE (2 levels) as the within-subject factor. Only the NoDis condition was analyzed since performance in this condition are a measurement of interest for characterizing attentional lapses.

MissRep were fitted to a linear model with binomial distribution without transformation, with fixed factors AGE and SES as between-subject factors and CUE (2 levels) and DISTRACTOR (4 levels) as within-subject factors.

CueRep and Randrep were fitted to a linear model with binomial distribution without transformation, with fixed factors AGE and SES as between-subject factors and CUE (2 levels) as the within-subject factor. As all participants made on average few CueRep and RandRep, responses were considered across all DISTRACTOR levels (NoDis, Dis1, Dis2, Dis3) and modeling was limited to two-way interactions.

DisRep were fitted to a linear model with binomial distribution without transformation, with fixed factors AGE and SES as between-subject factor and CUE (2 levels) as within subject factor. Responses were considered across DISTRACTOR levels (Dis1, Dis2, Dis3).

AntRep were fitted to a linear model with binomial distribution without transformation, with fixed factors AGE and SES as between-subject factors and CUE (2 levels) as the within- subject factor. Because of the important differences in the duration of the AntRep windows between distractor conditions, the GLMM was performed on the NoDis and Dis1 conditions, only (same time-frame for AntRep in these two conditions). 


\section{F. Distribution of behavioral responses made after the target occurrence}

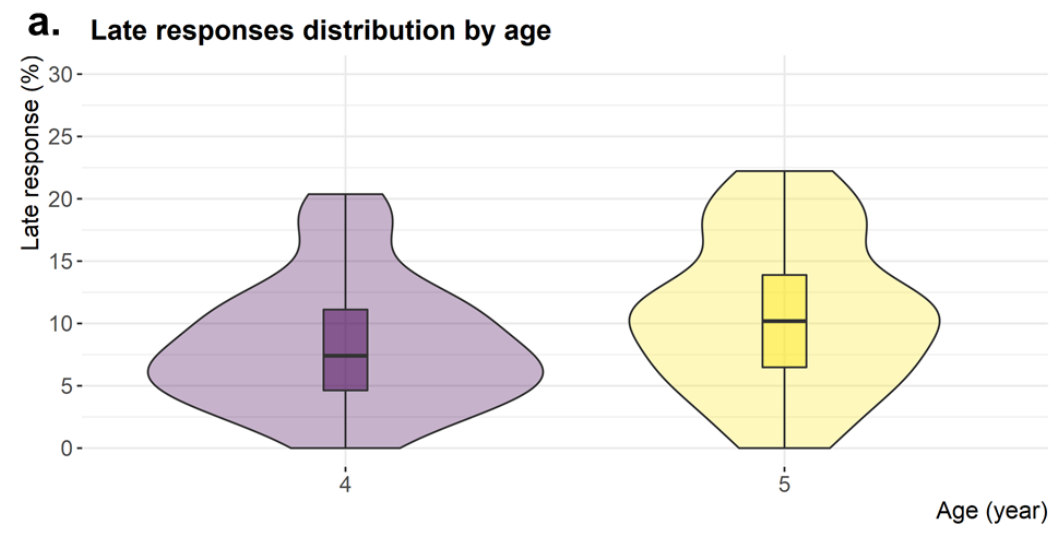

b. Missed responses distribution by age

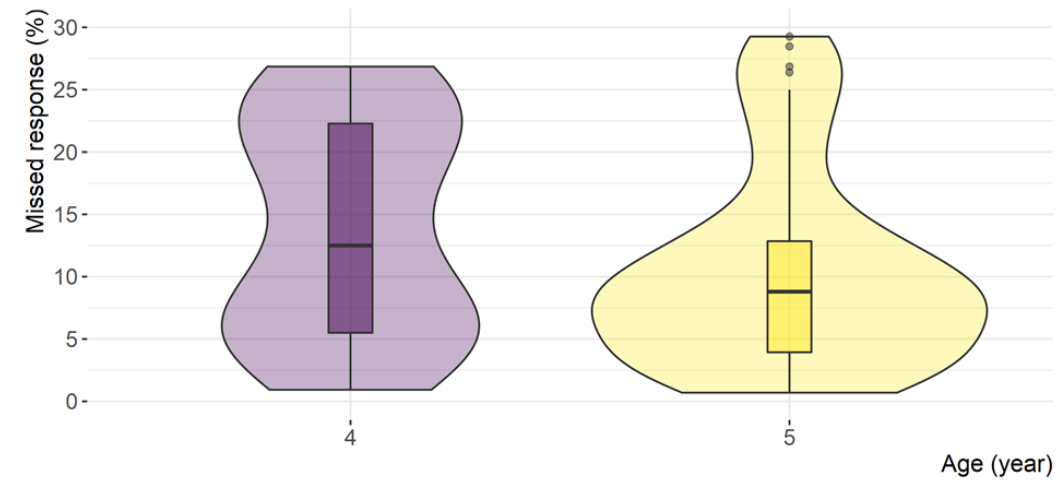

Fig. A6 | Behavioral responses made after target according to age. a, Missed responses percentage as function of the age. b, Late responses percentage as a function of the age. For $a$ and $b$ : within each boxplot (Tukey method), the horizontal line represents the median, the box delineates the area between the first and third quartiles (interquartile range); juxtapose to each boxplot, the violin plot adds rotated kernel density plot on each side. 


\section{G. Distribution of behavioral responses made before the target occurrence}

a. Cue responses distribution by age

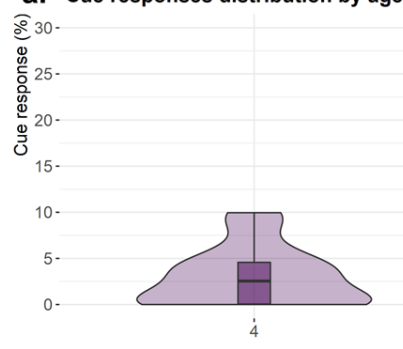

b. Random responses distribution by age

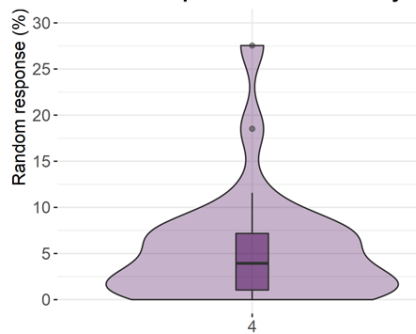

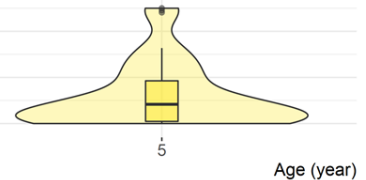

Age (year)

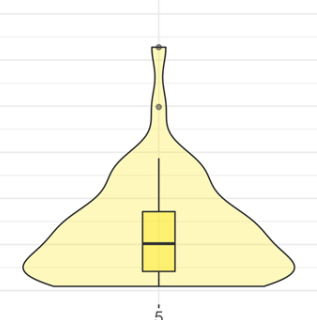

C. Distractor responses (Dis1, Dis2 and Dis3) distribution by age
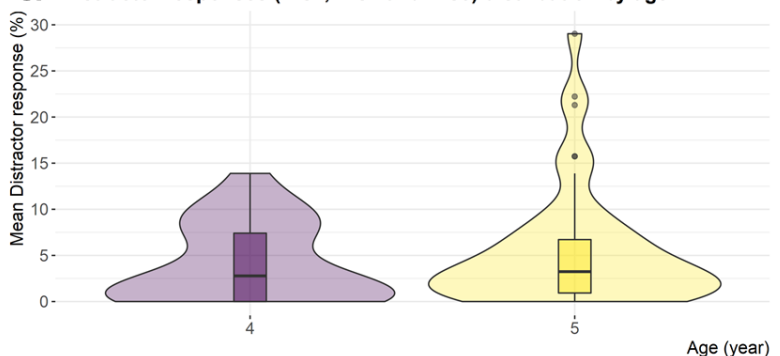

d. Anticipated responses (NoDis and Dis1) distribution by age

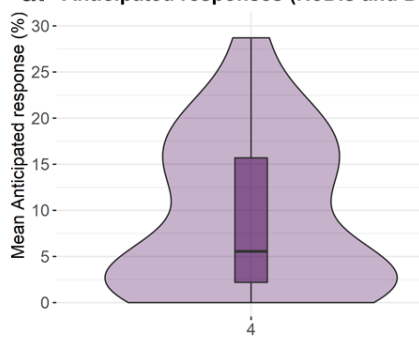

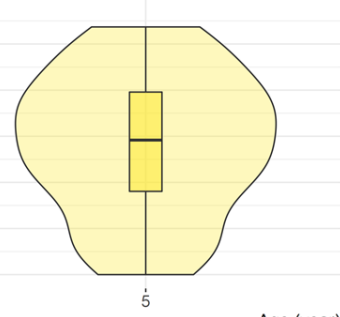

Age (year)

Age (year)

Fig. A7 | Behavioral responses made before target according to age. a, Cue responses percentage as function of the age. b, Random responses percentage as a function of the age. c, Distractor responses percentage as a function of the age. c, Anticipated responses percentage as a function of the age. For $a, b, c$ and d: within each boxplot (Tukey method), the horizontal line represents the median, the box delineates the area between the first and third quartiles (interquartile range); juxtapose to each boxplot, the violin plot adds rotated kernel density plot on each side. 
bioRxiv preprint doi: https://doi.org/10.1101/2021.04.06.438161; this version posted April 8, 2021. The copyright holder for this preprint (which was not certified by peer review) is the author/funder, who has granted bioRxiv a license to display the preprint in perpetuity. It is made available under aCC-BY-NC-ND 4.0 International license.

\section{H. Distribution of behavioral responses made before the target occurrence}

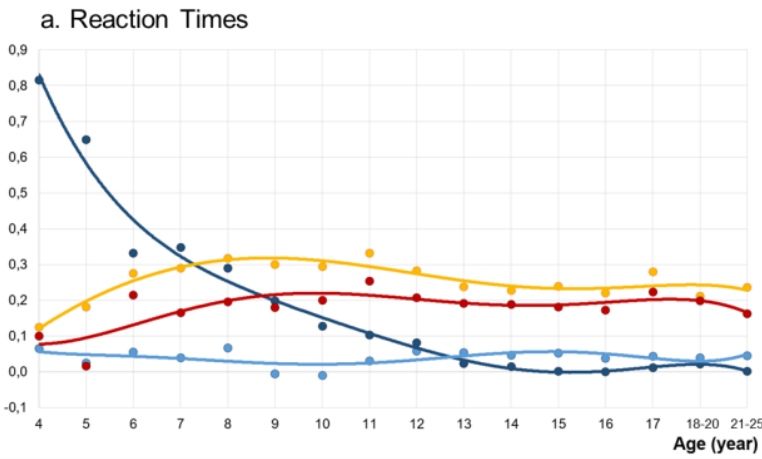

b. Response Types

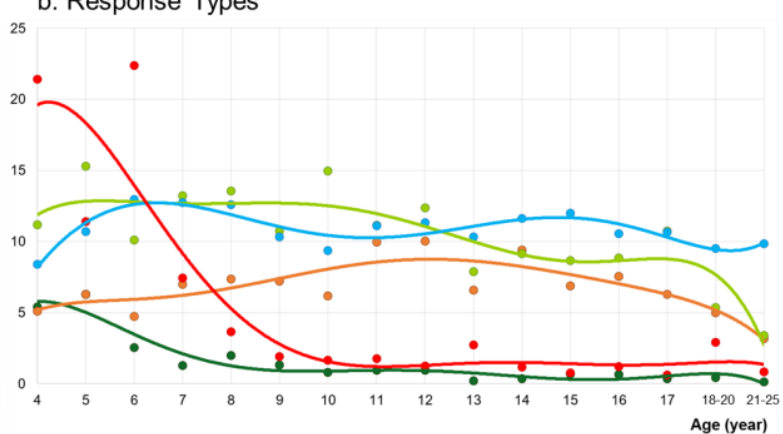

\begin{tabular}{|c|c|c|c|}
\hline Voluntary attention & Distraction & Motor control & Phasic arousal \\
\hline $\begin{array}{l}\text { Attentional orienting } \\
\text { index (RT) }\end{array}$ & $\begin{array}{l}\text { Distraction effect } \\
\text { index (RT) }\end{array}$ & Random responses & Arousal index ( $R T)$ \\
\hline $\begin{array}{l}\text { Sustained attention } \\
\text { index (RT) }\end{array}$ & Miss responses & \multicolumn{2}{|c|}{ Anticipated responses } \\
\hline Late responses & Distra & sponses & \\
\hline
\end{tabular}

Fig. A8 | Graphical representation of the developmental trajectories of the distractibility components measured by the CAT task: present and past findings. Note that this figure is based on a combination with the present results in preschool children and previous from a CAT study in school-aged children and adults a, Reaction times normalized measures according to age. Curves correspond to polynomial fitting curves for the Sustained Attention (order 4) and Arousal (order 4) measures, and to fitting lines for the Distraction and Attention Orienting measures. Sustained attention measure $=$ mean $\mathrm{RT} S \mathrm{SD}$ for each age range normalized across age ranges; Attention orienting measure $=\left(\mathrm{medianRT}_{\text {NoDisUninf }}-\right.$ medianRT $\left._{\text {NoDislnf }}\right) /$ medianRT $_{\text {All; }}$ Arousal measure $=\left(\right.$ medianRT $_{\text {NoDis }}-$ medianRT $_{\text {Dis } 1)} /$ medianRT $_{\text {All; }}$ Distraction effect measure $=\left(\right.$ medianRT $_{\text {Dis3 }}-$ medianRT Dis1) / medianRT All. b, Percentage of late responses (LateRep), miss responses (MissRep), responses to distractors (DisRep), anticipated responses (AntRep) and random responses (RandRep) according to age. Dots represent the mean percentage. Curves correspond to polynomial fitting curves for LateRep (order 6), MissRep (order 6) DisRep (order 6) and AntRep (order 6), and to a fitting line for RanRep. Measures reflecting (1) voluntary attention are in blue colors, (2) distraction are in red colors; (3) motor control are in green colors, and (4) arousal are in yellow color. Brown and light green colors represent processes overlaps. Dotted lines represent measures which have not been found modulated by age. 